\title{
Inhibition of COX-2 and EGFR by Melafolone Improves Anti-PD-1 Therapy through Vascular Normalization and PD-L1 Downregulation in Lung Cancer[\$
}

\author{
Honglin Tang, ${ }^{1}$ Yanzhuo Liu, ${ }^{1}$ Chenlong Wang, Hao Zheng, Yaxin Chen, Wen Liu, \\ Xuewei Chen, Jing Zhang, Honglei Chen, Yuqing Yang, and Jing Yang \\ Department of Pharmacology and Hubei Province Key Laboratory of Allergy and Immune-Related Diseases (H.T., Y.L., C.W., \\ H.Z., Y.C., W.L., X.C., J.Z., J.Y.) and Department of Pathology and Pathophysiology (H.C.), School of Basic Medical Sciences, \\ Wuhan University, Wuhan, China; and Department of Pharmaceutics, Ernest Mario School of Pharmacy, Rutgers, The State \\ University of New Jersey, Piscataway, New Jersey (Y.Y.)
}

Received October 11, 2018; accepted December 19, 2018

\begin{abstract}
Checkpoint blockade therapy has been proven efficacious in lung cancer patients. However, primary/acquired resistance hampers its efficacy. Therefore, there is an urgent need to develop novel strategies to improve checkpoint blockade therapy. Here we tested whether dual inhibition of cyclooxygenase-2 (COX-2) and epidermal growth factor receptor (EGFR) by flavonoid melafolone improves program death 1 (PD-1) checkpoint blockade therapy through normalizing tumor vasculature and PD-1 ligand (PD-L1) downregulation. Virtual screening assay, cellular thermal shift assay, and enzyme inhibition assay identified melafolone as a potential inhibitor of COX-2 and EGFR. In Lewis lung carcinoma (LLC) and CMT167 models, dual inhibition of COX-2 and EGFR by melafolone promoted survival, tumor growth inhibition, and vascular normalization, and ameliorated $\mathrm{CD}^{+} \mathrm{T}$-cell suppression,
\end{abstract}

accompanied by the downregulation of transforming growth factor- $\beta$ (TGF- $\beta$ ), vascular endothelial growth factor (VEGF), and PD-L1 in the tumor cells. Mechanistically, dual inhibition of COX2 and EGFR in lung cancer cells by melafolone increased the migration of pericyte, decreased the proliferation and migration of endothelial cells, and enhanced the proliferation and effector function of $\mathrm{CD}^{+}{ }^{+}$, cells through VEGF, TGF- $\beta$, or PD-L1 downregulation and PI3K/AKT inactivation. Notably, melafolone improved PD-1 immunotherapy against LLC and CMT167 tumors. Together, dual inhibition of COX-2 and EGFR by melafolone improves checkpoint blockade therapy through vascular normalization and PD-L1 downregulation and, by affecting vessels and immune cells, may be a promising combination strategy for the treatment of human lung cancer.

\section{Introduction}

Lung cancer remains one of the leading causes of cancer mortality in the world (Siegel et al., 2016). Even after maximal safe resection and chemoradiation, the 5-year survival rate is dismal (Raju et al., 2018). Checkpoint blockade therapy, including monoclonal antibodies against programmed cell death 1 (PD-1) and its ligand (PD-L1), is a breakthrough for multiple types of cancer, including non-small cell lung cancer (NSCLC) (Meyers et al., 2018). Unfortunately, a significant subset of patients does not respond to immunotherapy and another subset eventually develops resistance

This work was partly supported by the National Natural Science Foundation of China (Grant nos. 81872443 and 81173089 to J.Y.), and Hubei Key Laboratory of Medical Information Analysis and Tumor Diagnosis and Treatment (PJS140011707 to Y.L.). The authors have no competing financial interests to declare.

${ }^{1}$ H.T. and Y.L. contributed equally to this work.

https://doi.org/10.1124/jpet.118.254359.

S This article has supplemental material available at jpet.aspetjournals.org. after the initial response (O'Donnell et al., 2017). Thus, it is of great importance to develop novel strategies to improve checkpoint blockade therapy for lung cancer.

The infiltration of cytotoxic $\mathrm{CD} 8^{+} \mathrm{T}$ lymphocytes in tumors is a prerequisite for successful cancer immunotherapy (Chowdhury et al., 2018). However, high abnormalization of tumor blood vessels hinders the $\mathrm{CD} 8^{+} \mathrm{T}$-cell infiltration into tumor parenchyma and thus promotes tumor escape from immune attack (Wallin et al., 2016). Moreover, the abnormal tumor vasculature establishes a hypoxic microenvironment that induces immune regulatory proteins such as PD-1 and PD-L1 (Siemann and Horsman, 2015; Ruf et al., 2016). The PD-L1/PD-1 upregulation suppresses $\mathrm{CD}^{+}$ T-lymphocyte activation and proliferation, and thereby promotes the progression of solid tumors (Chen et al., 2015). Conversely, tumor vessel normalization with lowdose tumor necrosis factor- $\alpha$ substantially promotes the infiltration of $\mathrm{CD}^{+} \mathrm{T}$ lymphocytes and thereby improves antitumor vaccination or adoptive T-cell therapy in

ABBREVIATIONS: CFSE, carboxyfluorescein succinimidyl ester; CM, conditioned media; COX-2, cyclooxygenase-2; EGFR, epidermal growth factor receptor; ELISA enzyme-linked immunosorbent assay; EP4, prostaglandin E2 receptor 4; GzmB, granzyme B; IFN- $\gamma$, interferon- $\gamma$; IL-2, interleukin-2; LLC, Lewis lung carcinoma; Mel, melafolone, 2-methyl-butyric acid 2,4-dihydroxy-3,6-dimethoxy-5-[(E)-(3-phenyl-acryloyl)]-phenyl

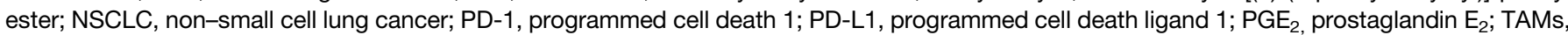
tumor-associated macrophages; TGF- $\beta$, transforming growth factor- $\beta$; VEGF, vascular endothelial growth factor. 
a preclinical model of insulinoma (Johansson et al., 2012). Normalization of tumor vasculature also enhanced extravasation of adoptively transferred $\mathrm{T}$ cells into tumors and improved adoptive cell transfer-based immunotherapy in B16 melanoma (Shrimali et al., 2010). However, whether tumor vascular normalization improves the anti-PD-1 immunotherapy for lung cancer has not been elucidated.

Cyclooxygenase-2 (COX-2) and its metabolite prostaglandin $\mathrm{E}_{2}\left(\mathrm{PGE}_{2}\right)$ upregulate PD-L1 in myeloid-derived suppressor cells and tumor-associated macrophages (TAMs) in murine MBT-2 bladder tumor (Prima et al., 2017). COX-2 expression is correlated with PD-L1 expression in resected tissue specimens of human lung adenocarcinoma (Shimizu et al., 2017). However, COX-2 inhibition had no impact on PD-L1 expression in the in vitro cultured NSCLC cells (Shimizu et al., 2018), suggesting that single blockade of COX-2 pathway may be insufficient to modulate PD-L1 in NSCLC. Epidermal growth factor receptor (EGFR) is frequently overexpressed in human lung cancers and correlates with poor patient outcome (Selvaggi et al., 2004; Arfaoui et al., 2014; Gately et al., 2014). The oncogenic EGFR signaling upregulates PD-L1 in lung cancer, whereas EGFR inhibition downregulates PD-L1 in NSCLC (Wang et al., 2017b; Li et al., 2018). Increasing evidence demonstrates that interactions between EGFR and COX-2 pathways affect tumor growth, angiogenesis, and metastasis in lung cancer (Li et al., 2016; Shi et al., 2017). Dual EGFR and COX-2 inhibition exerts additive antitumor growth and antiangiogenesis effects in lung cancer ( $\mathrm{Li}$ et al., 2016). However, whether dual EGFR and COX-2 inhibition expands the benefit of anti-PD-1 immunotherapy in lung cancer is largely unknown.

There is growing interest in exploring dietary flavonoids as antitumor immunity candidates (Lewandowska et al., 2016; Takac et al., 2018). We previously reported that flavonoid CH625 normalizes vasculature while accompanied by increased antitumor immunity in C6 and GL261gliomas (Wang et al., 2018). A recent study from another group demonstrated that flavone apigenin suppresses expression of PD-L1 and enhances proliferation of $\mathrm{T}$ cells in breast cancer (Coombs et al., 2016). However, whether the flavonoid improves the anti-PD-1 checkpoint blockade therapy has not been investigated. In this study, we demonstrated that melafolone (Mel, 2-methyl-butyric acid 2,4-dihydroxy-3,6-dimethoxy-5[(E)-(3-phenyl-acryloyl)]-phenyl ester), one of the pharmacologically active flavonoids from Polygonum lapathifolium, improves anti-PD-1 immunotherapy through vascular normalization and PD-L1 downregulation via a COX-2 and EGFRdependent mechanism. Our results may lead to a potential combination strategy to facilitate checkpoint blockade therapy in human lung cancer.

\section{Materials and Methods}

Plant Material and Mel Preparation. In this study, the root of Polygonum lapathifolium collected in Yili Prefecture, Xinjiang Province, China, was authenticated by Dr. Mingxi Jiang from Wuhan Institute of Botany, Chinese Academy of Sciences. The Mel was isolated, purified, and identified according to a previously described method (Ezhilan and Neelamegam, 2012). The purity of Mel measured by high-performance liquid chromatography was higher than $99 \%$. For in vivo studies, liposomal Mel was made by mixing cholesterol, 1,2-dimyristoyl-sn-glycero-3-phosphocholine and Mel at a mole ratio of 5:5:1, according to previously described method (Wang et al., 2018).
For in vitro studies, Mel was dissolved in dimethyl sulfoxide as a stock solution $(80 \mathrm{mM})$, stored at $-20^{\circ} \mathrm{C}$, and the serial dilution was performed in cell culture medium (final dimethyl sulfoxide concentration $\leq 1 \%$ ).

Cell Culture and Lentiviral Transduction. The human A549 lung cancer cells, mouse Lewis lung carcinoma (LLC) cells, mouse endothelial cells MS1, mouse pericyte-like cell 10T1/2, and human umbilical vein endothelial cells (HUVEC) were obtained from the American Type Culture Collection (ATCC, Manassas, VA). Murine CMT167 lung cancer cell line was purchased from the Cancer Research UK Central Cell Service (Clare Hall, Middlesex, UK). Human $\mathrm{CD}^{+} \mathrm{T}$ cells were isolated from the blood of healthy volunteers in accordance with the Helsinki Declaration. All volunteers gave written informed consent, and the experiment was approved by the Institutional Review Board of the Wuhan University. Mouse tumor cells and $\mathrm{CD}^{+} \mathrm{T}$ cells were isolated and purified from tumors with a mouse tumor cell or $\mathrm{CD}^{+}$T-cell isolation kit (Miltenyi Biotech, Auburn, CA). The cells were grown in RPMI 1640 or Dulbecco's modified Eagle's medium with $10 \%$ fetal bovine serum in the humidified incubator. Mycoplasma testing for all cell lines was performed every 3 months using the MycoAlert Mycoplasma Detection Kit (Lonza, Slough, UK).

LLC and A549 cells were placed in a six-well tissue culture plate at the density of $2 \times 10^{5}$. Cells at $80 \%$ confluence in the plate were transduced with COX-2, PD-L1, or Akt lentiviral activation particles (Santa Cruz Biotechnology) for 24 hours. The negative control lentivirus was transduced in the cells as control. The protein expression COX-2, PD-L1, and Akt was determined by Western blot.

Molecular Docking Study. Structure-based virtual screening was performed in accordance with a previously described method (Sogabe et al., 2012; Liu et al., 2018). Briefly, human EGFR (PDB id: 3W2S) and COX-2 (PDB id: 5IKT) crystal structures were obtained from the protein data bank (PDB). The active sites were defined by the cocrystallized inhibitors of the COX-2 and EGFR. The candidates were filtered by Lipinski's rule of five utilizing SYBYL-X 2.0 (Tripos, St. Louis, MO). The SYBYL software was used to assign the standard Assisted Model Building with Energy Refinement (AMBER) atomic partial charges on the COX-2 and EGFR proteins and the GasteigerHückel atomic partial charges on the ligand candidates to be docked. After these procedures, the docking was carried out in SYBYL software under default setting, and the figures were obtained by utilizing PyMol (http://www.pymol.org).

Cellular Thermal Shift Assay. Cellular thermal shift assay (CETSA) was conducted using cell lysates as previously described (Dai et al., 2018). For the temperature-dependent thermal shift assay, $50 \mu \mathrm{l}$ of lysates $(3 \mathrm{mg} / \mathrm{ml}$ ) from A549 cells were incubated with $20 \mu \mathrm{M}$ of $\mathrm{Mel}$ at each temperature point from $36^{\circ} \mathrm{C}$ to $80^{\circ} \mathrm{C}$ for 4 minutes. The supernatant and pellet were separated from the above samples by centrifugation at $20,000 \mathrm{~g}$ for 10 minutes. Twelve microliters of the supernatant was mixed with $3 \mu \mathrm{l}$ of $5 \times$ loading buffer and then separated on a $10 \%$ SDS-PAGE for immunoblotting analysis of COX-2 or EGFR. For the dose-dependent thermal shift assay, $50 \mu \mathrm{l}$ of lysates $(3 \mathrm{mg} / \mathrm{ml}$ ) were incubated with various concentrations of Mel (between 0.001 and $1000 \mu \mathrm{M}$ ) at $52^{\circ} \mathrm{C}$ for 4 minutes. Supernatants were isolated by centrifugation and subjected to immunoblotting analysis of COX-2 or EGFR as described above.

Tumor Model and Treatment Regimen. C57BL/6 mice (male, 6-8 weeks old, 16-20 g) were provided by the Center for Disease Control and Prevention (Hubei, China). The mice were housed in the pathogen-free environment on a 12-hour dark and 12-hour light cycle with ad libitum access to water and food. The animal experiments were carried out in accordance with the guidelines of the animal ethics committee of the Animal Research Committee of Wuhan University.

In the LLC or CMT167 subcutaneous tumor model, LLC $\left(2 \times 10^{5}\right)$ or CMT167 $\left(2 \times 10^{5}\right)$ cells were subcutaneously injected in the right flank of C57BL/6 mice. Seven days later when the tumors had reached a size of about $100 \mathrm{~mm}^{3}$, the mice were intraperitoneally administered Mel (20 and $40 \mathrm{mg} / \mathrm{kg}$ daily) or vehicle. The dose of Mel was selected 
according to the preliminary experiments. For the combination experiments, mice were administered anti-PD-1 antibody (cat. no. BE0146; Bio X Cell, West Lebanon, NH; $200 \mu \mathrm{g} /$ mouse every 3 days, i.p.), $\mathrm{Mel}$ (20 mg/kg daily, i.p.), anti-PD-1 antibody plus Mel, or vehicle. The dose of anti-PD-1 antibody was selected according to previous study (Tan et al., 2018). One-half of the mice in the LLC or CMT167 models were sacrificed on day 15 or day 21 after tumor implantation, and the tumor tissues and the peripheral blood were collected and analyzed. The remaining mice were used for the survival study. Mice were sacrificed when they became moribund or when the tumor length reached $2 \mathrm{~cm}$. Survival was assessed from the 1st day of implantation until death.

Tumor Perfusion Measurement. Laser Doppler analysis of tumor perfusion was carried out according to previously described method (Wang et al., 2018). Briefly, 0.6\% pentobarbital was used to anesthetize the LLC tumor-bearing mice described above. We then placed the mice on the $37^{\circ} \mathrm{C}$ heating pad and carefully excised the skin capsule over the tumor to protect the vascular network. Tumor perfusion in mice administered $\mathrm{Mel}$ or vehicle at days $0,2,4,6$, and 8 was blindly determined by utilizing the laser Doppler analyzer (LDPI; Moor Instruments, Axminster, UK). The tumor perfusion in arbitrary perfusion units was monitored graphically.

Analysis for Serum Biochemical Parameters. The peripheral blood from the mice administered anti-PD-1 antibody (200 $\mu \mathrm{g} / \mathrm{mouse})$, $\mathrm{Mel}(20 \mathrm{mg} / \mathrm{kg}$ ), anti-PD-1 antibody plus Mel, or vehicle was collected. Complete blood counts, including red blood corpuscles, white blood corpuscles, platelet, mean cell volume, and hematocrit levels, were measured by Sysmex XE-2100 (TOA Medical Electronics, Kobe, Japan), and the blood urea nitrogen, plasma alanine aminotransferase, aspartate aminotransferase, creatine kinase-MB, and creatine levels were measured by Beckman LX20 (Beckman-Coulter, Brea, CA) according to a previous study (Li et al., 2013).

Immunofluorescence. The tumor tissues from the mice administered Mel or vehicle were incubated with anti-CD31 (1:100, ab24590; Abcam, Cambridge, MA) and anti-smooth muscle actin (1:100, ab32575; Abcam) antibodies at $4^{\circ} \mathrm{C}$ overnight. Tissues were then hatched with secondary antibodies conjugated with Alexa Fluor
594 or 488 for 1 hour. After a washing, the tissues were mounted with fluorescent mounting medium containing DAPI. Each section was observed by an Olympus BX51 microscope.

Western Blot Analysis. Proteins in the LLC, CMT167, A549, or human and mouse $\mathrm{CD}^{+}{ }^{+} \mathrm{T}$ cells were extracted, and protein concentrations were measured according to the Bradford method. Protein extracts were resolved by SDS-PAGE and transferred to polyvinylidene fluoride membranes. The membranes blocked by $5 \%$ nonfat milk were probed with antibodies against EGFR (1:5000, ab52894; Abcam), p-EGFR (1:3000, ab182618; Abcam), hypoxia-induced factor (HIF)-1 $\alpha$ (1:1000, sc-13515; Santa Cruz Biotechnology, Dallas, TX), PD-L1 (1:1000, ab213480; Abcam), granzyme B (GzmB) (1:1000, ab53097; Abcam), IFN- $\gamma$ (1:5000, ab133566; Abcam), interleukin-2 (IL-2) (1:2000, ab180780; Abcam), prostaglandin E2 receptor 4 (EP4; 1: 1000, sc-55596; Santa Cruz Biotechnology), Akt (1:500, ab8805; Abcam), p-Akt (1:1000, ab38449; Abcam), or $\beta$-actin (1:3000, ab227387; Abcam) at $4^{\circ} \mathrm{C}$ overnight. After a washing, the blots were stained with peroxidase-conjugated antibody, and the enhanced chemiluminescence kit was used for chemiluminescence detection.

Analysis of Gene Expression. Total RNA was isolated with Trizol (Invitrogen, Carlsbad, CA), and reverse-transcribed to cDNA by a PrimeScript RT Reagent Kit with gDNA Eraser (Takara, Dalian, Liaoning, China) according to the manufacturer's protocol. The reaction of real-time PCR mixtures containing SYBR Green was composed in accordance with the manufacturer's instructions (Takara). Quantification was carried out utilizing the $2^{-\Delta \Delta \mathrm{Ct}}$ method. The primers of vascular endothelial growth factor (VEGF), transforming growth factor- $\beta$ (TGF- $\beta$ ), PD-L1, GzmB, IL- 2 and IFN- $\gamma$ were designed on the basis of previously published sequences (Allen et al., 2017; Chen et al., 2017a; Tan et al., 2018). Primers used in this study were shown in Supplemental Table 1. Target gene expression level was normalized to GAPDH (Duan et al., 2018).

Conditioned Media Preparation. The conditioned media (CM) from LLC and A549 cells was made in accordance with a previously described method (Chen et al., 2017a). Briefly, the LLC and A549 cells
A
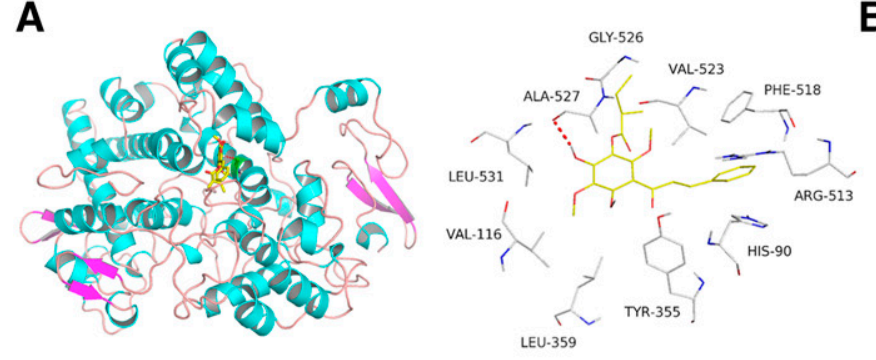

D


B
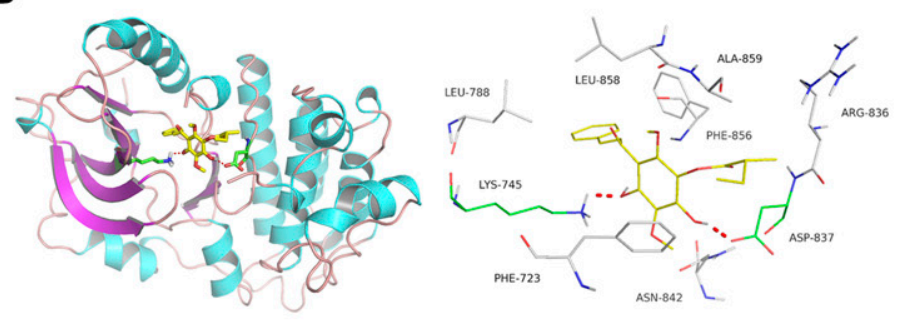

E

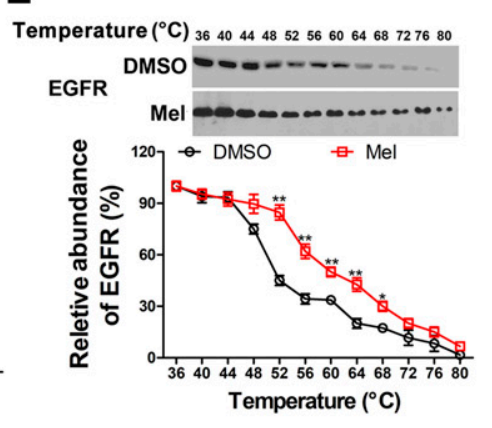

F

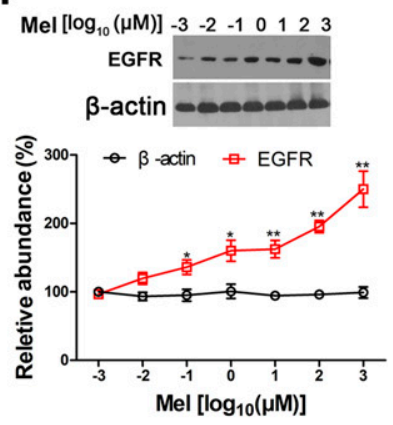

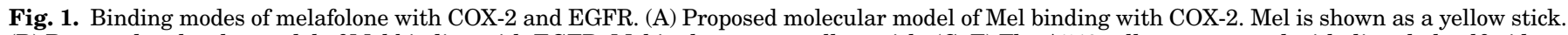

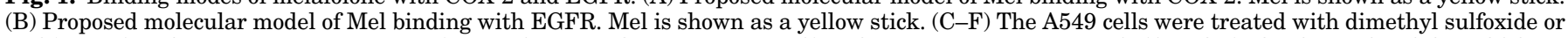

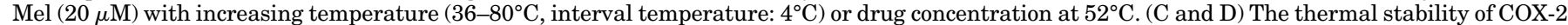

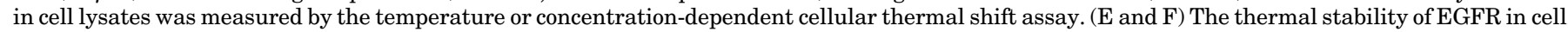

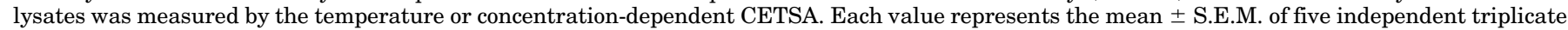
experiments. $* P<0.05 ; * * P<0.01$ vs. control. 
in six-well plates were administered $\operatorname{Mel}(10$ and $20 \mu \mathrm{M})$ or vehicle for 24 hours. The cell supernatants from the above-treated cells were then centrifuged and filtered through an Amicon Ultra-4 filter to exclude the trace of Mel. The retentate was gathered as CM.

Enzyme-Linked Immunosorbent Assay. TGF- $\beta$, VEGF, or $\mathrm{PGE}_{2}$ levels in the LLC and CMT167 cells isolated from the Mel (20 and $40 \mathrm{mg} / \mathrm{kg}$ )-treated LLC and CMT167 tumors and the culture supernatants from Mel (10 and $20 \mu \mathrm{M})$-treated LLC and A549 cells were determined using enzyme-linked immunosorbent assay (ELISA) kits. IFN- $\gamma$, GzmB, and IL-2 in the $\mathrm{CD}^{+}{ }^{+} \mathrm{T}$ cells isolated from the Meltreated LLC and CMT167 tumors and the culture supernatants from the human and mouse $\mathrm{CD}^{+} \mathrm{T}$ cells were determined by ELISA kits (R\&D Systems, Minneapolis, MN).

Flow Cytometry. T cells were stained with FITC-labeled antiCD8 antibody and allophycocyanin (APC)-labeled anti-CD3 antibody (BD Biosciences, San Jose, CA). FACS data were obtained on the FACS Aria III flow cytometer and evaluated by utilizing the FlowJo software (Tree Star, Ashland, OR). The proliferation of CD8 ${ }^{+} \mathrm{T}$ cells was measured by flow cytometry in accordance with the manufacturer's instructions (BD Biosciences). Plate-bound anti-CD28 antibody and anti-CD3 antibody were used to stimulate T cells. After stimulation, the $\mathrm{T}$ cells were treated with the CM from LLC and A549 cells for 24, 48, and 72 hours. CD ${ }^{+}$T cells were determined by carboxyfluorescein succinimidyl ester (CFSE) dilution.

Cell Proliferation Assay. The cell proliferation assay was carried out according to a method described previously (Wang et al., 2017a). LLC and A549 cells were placed in 96-well plates at a density of $1 \times 10^{4} /$ well. The cells were collected after exposure to serial concentrations of Mel for 24 hours. Cell viability was measured by MTS (CellTiter 96 AQueous Assay reagent; Promega, Madison, WI) in accordance with the manufacturer's protocol. 5-Bromo-2'-deoxyuridine (BrdU) incorporation was measured with a cell proliferation ELISA kit (Roche Diagnostics, Indianapolis, IN) in accordance with the manufacturer's instructions. HUVEC or MS1 $\left(1 \times 10^{4} /\right.$ well $)$ seeded in 96 -well plates was incubated with the CM from LLC or A549 cells for
24 hours. The cell viability was determined in accordance with the instruction of MTS.

Migration Assay. The migration assay was carried out in accordance with a method described previously (Wang et al., 2018). Human brain vascular pericytes (HBVP), 10T1/2, HUVEC, or MS1 $\left(1 \times 10^{4} /\right.$ well $)$ were placed in the upper chamber, and $0.6 \mathrm{ml} \mathrm{CM}$ from LLC or A549 cells was placed in lower chamber. The nonmigrated cells in the upper chamber were removed. The cells migrating through the pores to the lower chamber were fixed and stained with $0.1 \%$ crystal violet blue. The stained cells in the lower chamber were counted.

Statistical Analysis. The Kolmogorov-Smirnov test was used to evaluate normal distribution of the data. Normal distributed data were then tested by one-way analysis of variance (ANOVA) followed by two-tailed Student's $t$ test or Student-Newman-Keul's test. One-way repeated measures ANOVA and Bonferroni's post-hoc test were performed to evaluate the statistical significance of changes over time. The Kaplan-Meier method and the log-rank test were used to estimate the survival rates. Data are presented as mean \pm S.E.M., and $P$ values of 0.05 or less were regarded as statistically significant.

\section{Results}

Mel is a Potential Inhibitor of COX-2 and EGFR. To explore the potential application of COX-2 and EGFR as drug targets, traditional Chinese medicine database (TCM Database@Taiwan) was used to perform virtual screening. We narrowed our focus from the 36,043 total compounds to the 15 top flavonoids as potential COX-2 and EGFR inhibitors (Supplemental Table 2). Among the 15 hits, Mel (ZINC14640449) showed strong interaction with COX-2 and EGFR with the docking energies of 5.52 and 9.92, respectively. COX-2/EGFR inhibitors interact with TYR355 and ALA527 of COX-2 and PHE856 of EGFR (Blobaum and

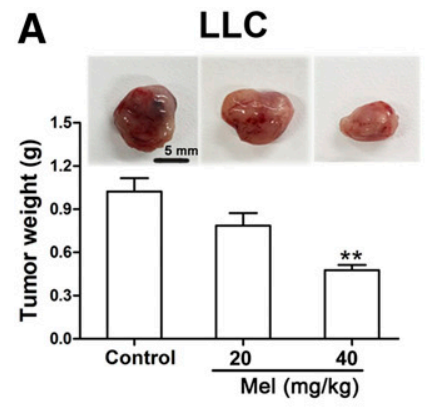

E

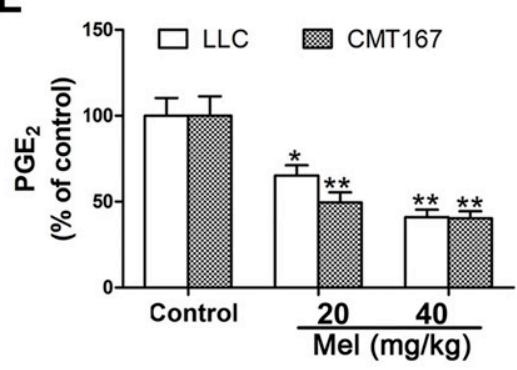

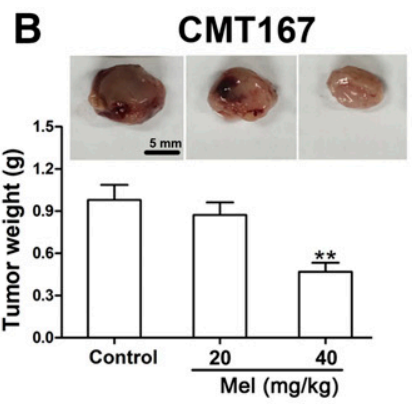

C LLC

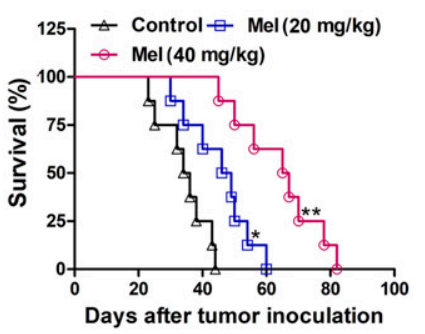

D $\quad$ CMT167

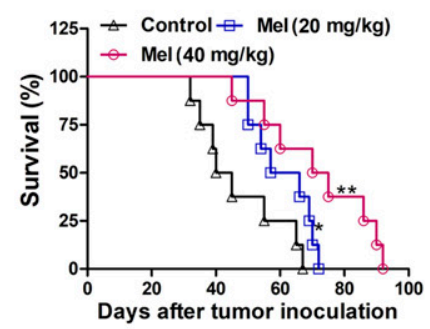



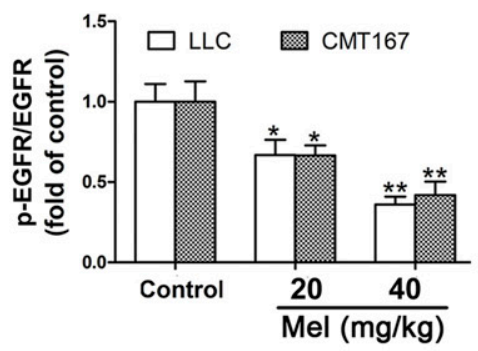

Fig. 2. Melafolone prolongs survival and delays tumor growth in Lewis lung carcinoma and CMT167 tumors. (A) LLC $\left(2 \times 10^{5}\right)$ were injected subcutaneously into the right flank of C57BL/6 mice. When tumors had reached a size of about $100 \mathrm{~mm}^{3}$, Mel was administered intraperitoneally at a dose of 20 and $40 \mathrm{mg} / \mathrm{kg}$ in mice once daily for 7 days. Tumor weight was measured in the LLC model. (B) CMT167 cells $\left(2 \times 10^{5}\right)$ were injected subcutaneously into the right flank of C57BL/6 mice. When tumors had reached a size of about $100 \mathrm{~mm}^{3}$, Mel was administered intraperitoneally at the dose of 20 and $40 \mathrm{mg} / \mathrm{kg}$ in mice once daily for 14 days. Tumor weight was measured in the CMT167 model. (C and D) The survival time of the mice

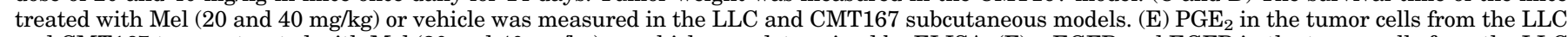
and CMT167 tumors treated with Mel $(20$ and $40 \mathrm{mg} / \mathrm{kg})$ or vehicle was determined by ELISA. (F) p-EGFR and EGFR in the tumor cells from the LLC and CMT167 tumors by Western blot. The values are presented as the mean \pm S.E.M., $n=8, * P<0.05 ; * * P<0.01$ vs. control. 
Marnett, 2007; Li et al., 2012; Alanazi et al., 2015). We demonstrated that Mel formed a hydrophobic interaction with the key catalytic-site residue TYR355 and interacted with the ALA527 of COX-2 through a hydrogen bond (H-bond) (Fig. 1A). Mel formed H-bonds with LYS745 and ASP837 and had a lipophilic interaction with PHE856 of EGFR (Fig. 1B). To further validate the binding of Mel to Cox-2 and EGFR, we performed the CETSA in human A549 cells. The thermal stability of human EGFR and COX-2 in the Mel-treated A549 cells was enhanced with increased temperatures $\left(36^{\circ} \mathrm{C}-80^{\circ} \mathrm{C}\right)$ and Mel concentration (0.001-1000 $\mu \mathrm{M}$ ) (Fig. 1, C-F), suggesting a direct interaction between $\mathrm{Mel}$ and human COX-2 or EGFR. Previous studies had shown that human EGFR and mouse EGFR are highly homologous (Ebben et al., 2016;

A
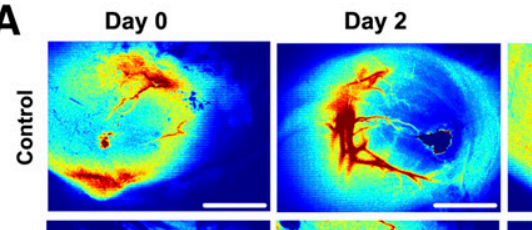

Day 4

Day 6

Day 8
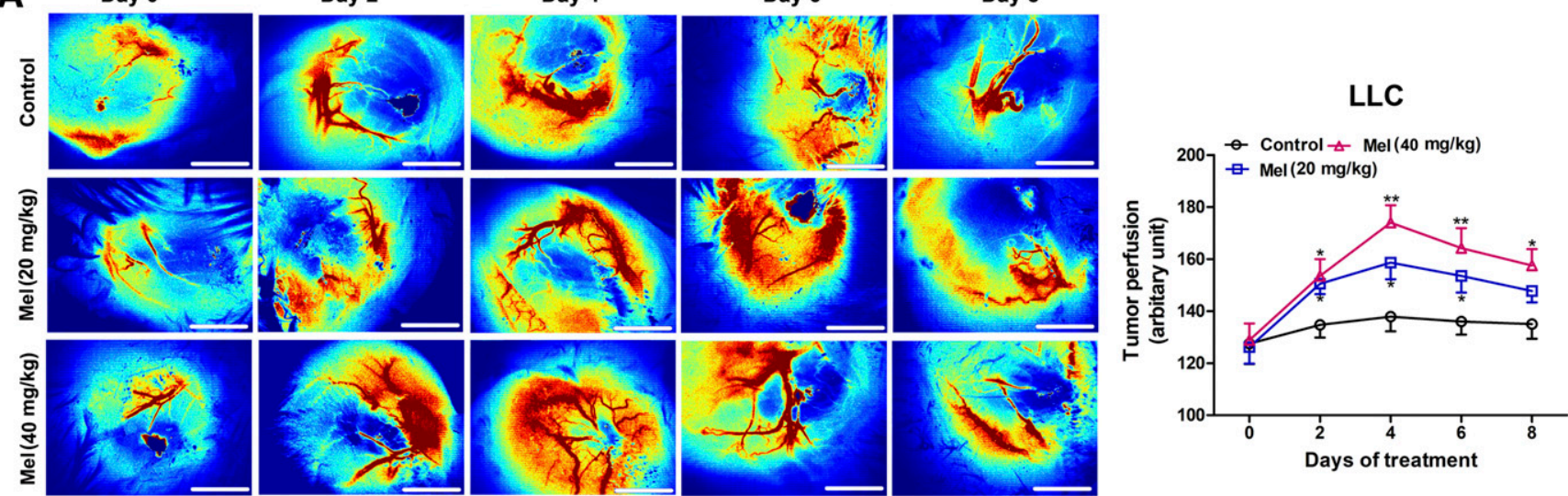

Blood flow color gradient

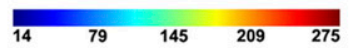

B
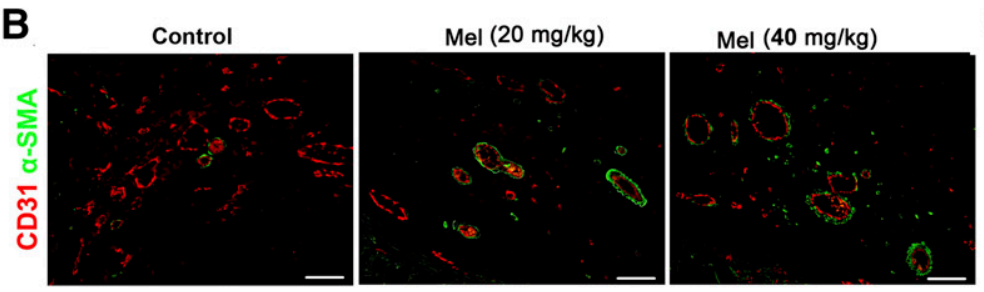

C

LLC

LLC
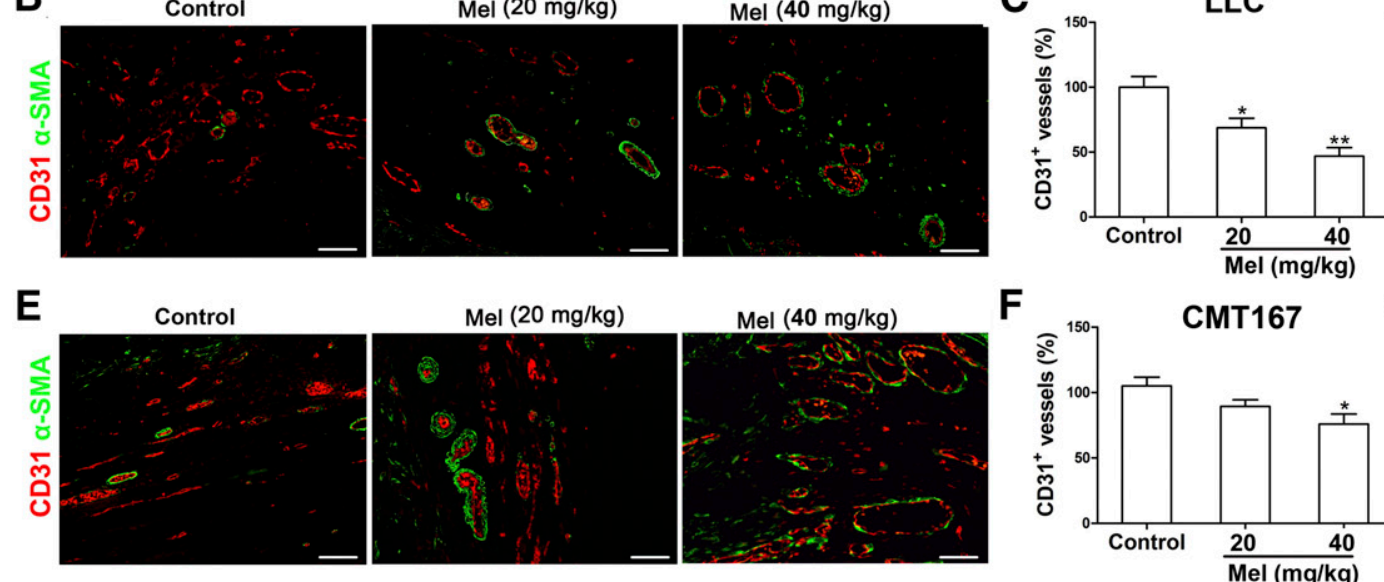

D
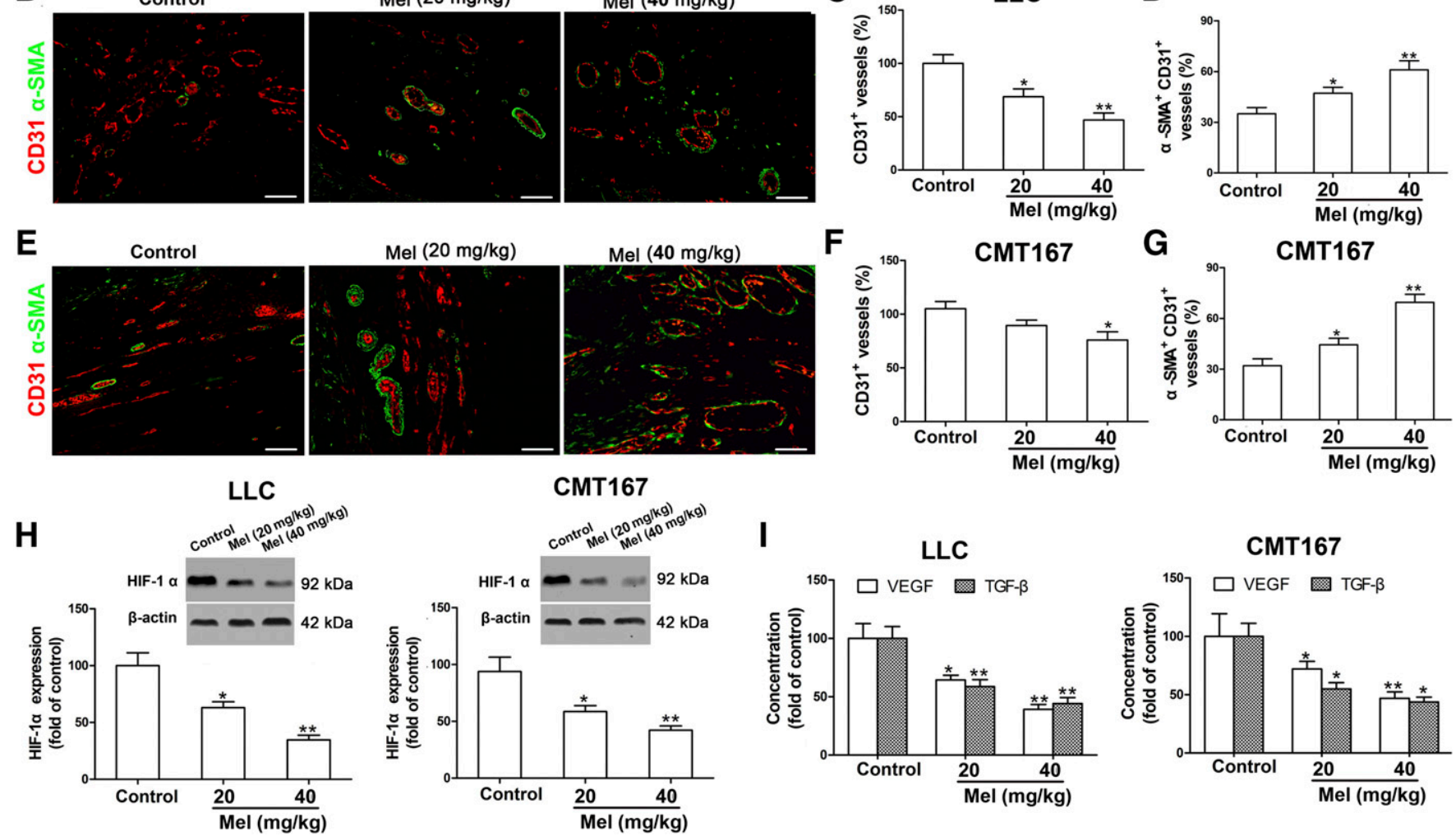

I

LLC

CMT167
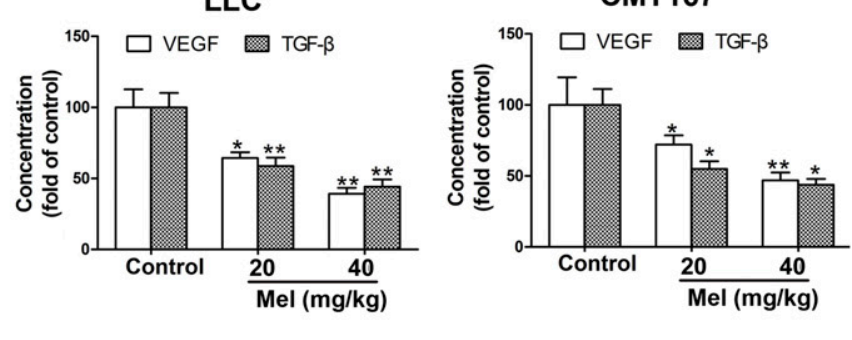

Fig. 3. Melafolone promotes vascular normalization in Lewis lung carcinoma and CMT167 tumors. LLC $\left(2 \times 10^{5}\right)$ or CMT167 cells $\left(2 \times 10^{5}\right)$ were injected subcutaneously into the right flank of $\mathrm{C} 57 \mathrm{BL} / 6 \mathrm{mice}$. When tumors had reached a size of about $100 \mathrm{~mm}^{3}$, Mel was administered intraperitoneally at the dose of 20 and $40 \mathrm{mg} / \mathrm{kg}$ in mice once daily for 7 or 14 days, respectively. (A) Tumor perfusion at days $0,2,4,6$, and 8 of treatment was measured using a laser Doppler analyzer in the LLC tumor model. Scale bar, $2 \mathrm{~mm}$. The quantitative analysis showed the relative levels of tumor perfusion in the LLC tumors. (B) Double staining for CD31 (red) and $\alpha$-smooth muscle actin ( $\alpha$-SMA; green) in the LLC tumor tissues was shown. Scale bar, $50 \mu \mathrm{m}$. (C) Quantitative analysis of CD31 ${ }^{+}$vessels in the LLC tumor tissues. (D) Quantitative analysis of CD31 ${ }^{+} \alpha-\mathrm{SMA}^{+}$vessels in the LLC tumor tissues. (E) Double staining for CD31 (red) and $\alpha$-SMA (green) in the CMT167 tumor tissues was shown. Scale bar, $50 \mu \mathrm{m}$. (F) Quantitative analysis of CD31 ${ }^{+}$vessels in the CMT167 tumor tissues. (G) Quantitative analysis of CD31 ${ }^{+} \alpha$-SMA ${ }^{+}$vessels in the CMT167 tumor tissues. (H) Hypoxia-induced factor (HIF)- $1 \alpha$ in the LLC and CMT167 tumor tissues was determined by Western blot. (I) VEGF and TGF- $\beta$ in the tumor cells from LLC and CMT167 tumors were measured by ELISA. The values are presented as the mean \pm S.E.M., $n=8,{ }^{*} P<0.05$; $* * P<0.01$ vs. control. 
A



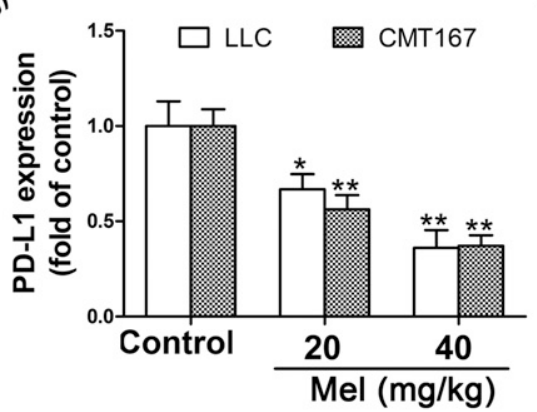

B

LLC

C
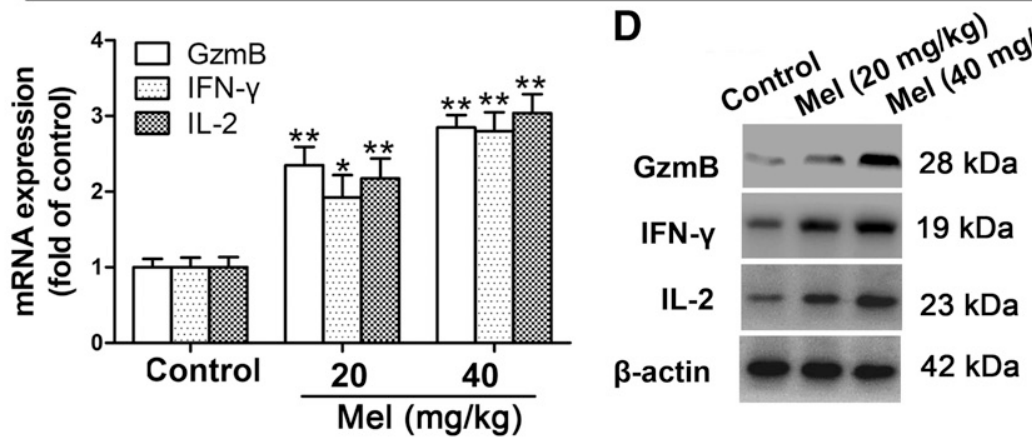

\section{CMT167}

\section{E}

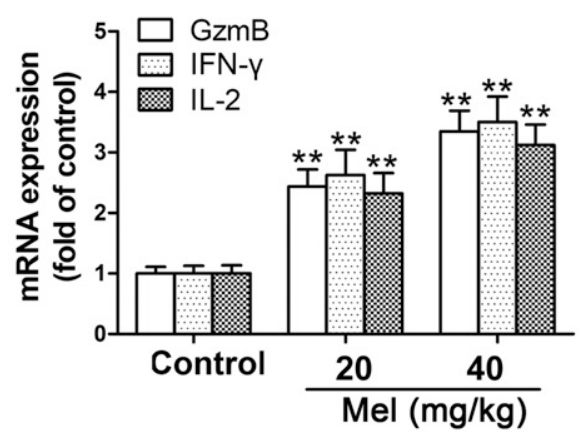

F

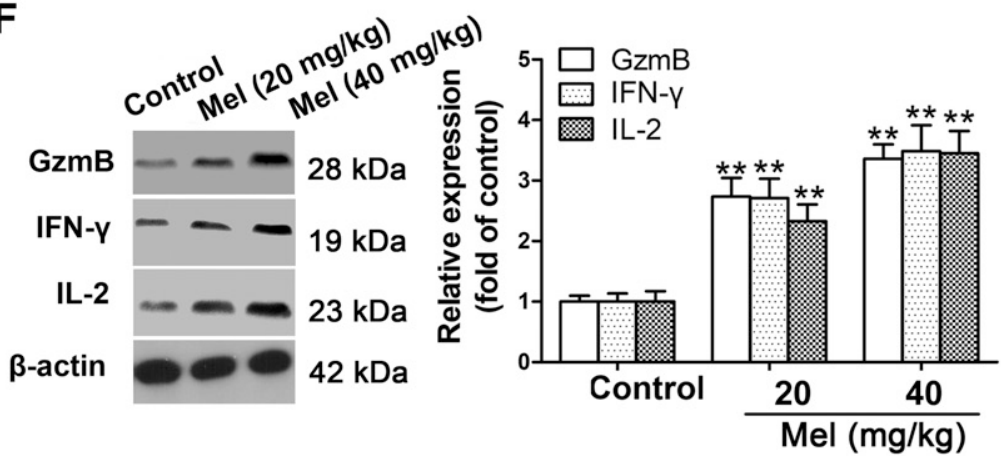

Fig. 4. Melafolone downregulates PD-L1 and enhances the infiltration and effector function of CD8 ${ }^{+} \mathrm{T}$ cells in the Lewis lung carcinoma and CMT167 tumors. (A) PD-L1 in tumor cells from the LLC and CMT 167 tumors treated with Mel (20 and $40 \mathrm{mg} / \mathrm{kg}$ ) or vehicle was measured by Western blot. (B) The number of CD8 ${ }^{+} \mathrm{T}$ cells in the LLC and CMT167 tumors treated with Mel (20 and $40 \mathrm{mg} / \mathrm{kg}$ ) or vehicle was determined by flow cytometry. (C and D) GzmB, IFN- $\gamma$, and IL-2 in the CD8 ${ }^{+}$T cells from the LLC tumors were determined by quantitative PCR and Western blot. (E and F) GzmB, IFN- $\gamma$, and IL-2 in the CD8 ${ }^{+} \mathrm{T}$ cells from the CMT167 tumors were determined by quantitative PCR and Western blot. The values are presented as the mean \pm S.E.M., $n=8, * P<0.05 ; * * P<0.01$ vs. control.

Kikuchi et al., 2016). We found that the human and mouse EGFR have $92 \%$ query coverage and $90 \%$ identity, and the human and mouse COX-2 have 97\% query coverage and $87 \%$ identity according to NCBI Protein BLAST. The thermal stability of mouse EGFR and COX-2 in the Mel-treated LLC cells was also enhanced compared with the control (Supplemental Fig. 1). Furthermore, we found that Mel inhibited COX-2-catalyzed $\mathrm{PGE}_{2}$ production, with an $\mathrm{IC}_{50}$ value of $13.2 \mu \mathrm{M}$, and EGFR phosphorylation, with the $\mathrm{IC}_{50}$ value of $17.4 \mu \mathrm{M}$, in A549 cells. Enzyme kinetic analysis showed that Mel is a competitive inhibitor of COX-2, since the $K_{\mathrm{m}}$ value was enhanced but the $V_{\max }$ was unchanged (Supplemental Fig. 2). Together, these results indicate that $\mathrm{Mel}$ is a potential inhibitor of COX-2 and EGFR.

Mel Prolongs Survival and Delays Tumor Growth in the LLC and CMT167 Tumors. The mice bearing subcutaneous LLC and CMT167 tumors were administered Mel
(20 and $40 \mathrm{mg} / \mathrm{kg}$ ) or vehicle. We found that $\mathrm{Mel} 40 \mathrm{mg} / \mathrm{kg}$ significantly reduced LLC and CMT167 tumor weight but Mel $20 \mathrm{mg} / \mathrm{kg}$ did not (Fig. 2, A and B). Mel (20 and $40 \mathrm{mg} / \mathrm{kg}$ ) significantly increased survival in the LLC or CMT167bearing mice compared with control mice (Fig. 2, C and D). Furthermore, Mel (20 and $40 \mathrm{mg} / \mathrm{kg}$ ) decreased the level of $\mathrm{PGE}_{2}$ and p-EGFR in tumor cells from LLC and CMT167 tumors without influencing EGFR (Fig. 2, E and F). These data indicate that Mel prolongs survival and delays tumor growth in the LLC and CMT167 tumors.

Mel Promotes Vascular Normalization and Ameliorates CD8 $^{+}$T-Cell Suppression in LLC and CMT167 Tumors. Previous studies showed that normalization of tumor vasculature delays tumor growth, and functional normalization is an essential element in the vascular normalization paradigm (Qin et al., 2015). Thus, we used laser Doppler 


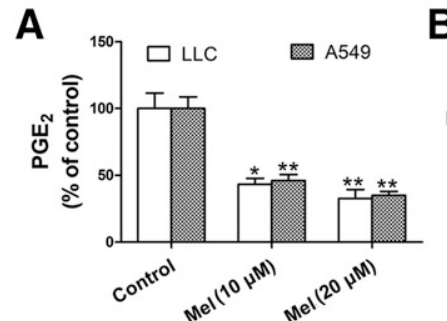

D

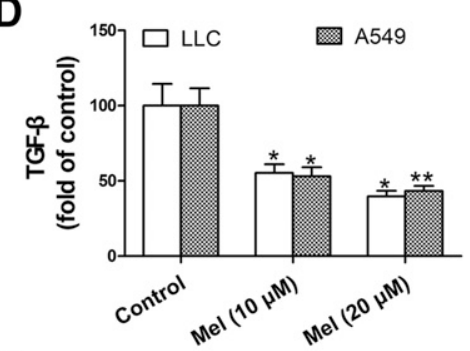

G

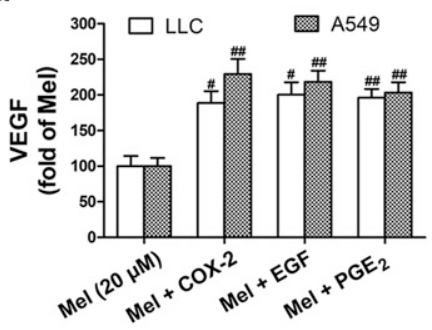

B

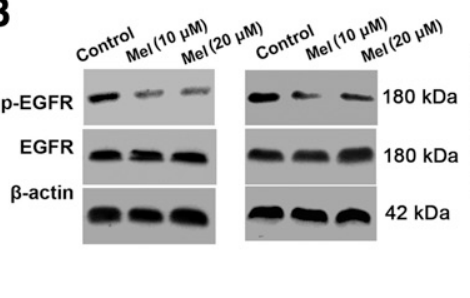

$E$

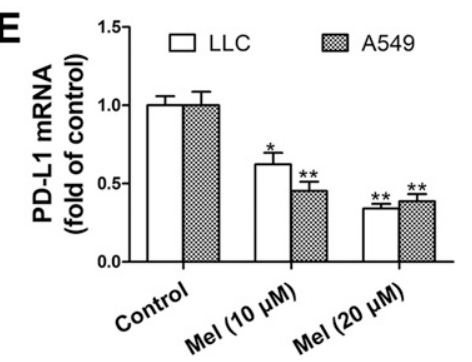

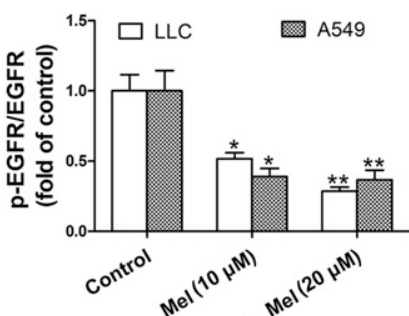

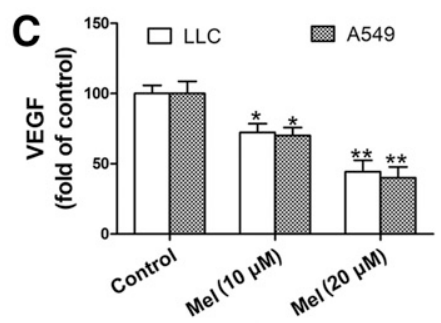

$\mathbf{F}$
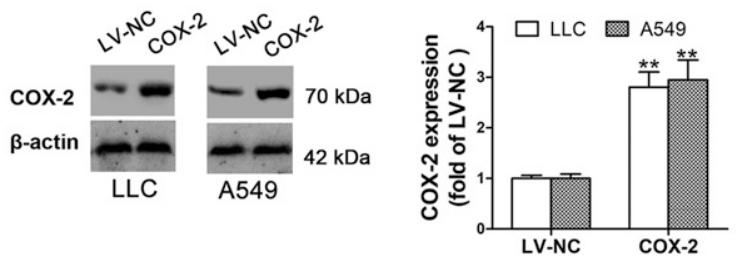

Fig. 5. Melafolone blocks VEGF, TGF- $\beta$, and PD-L1 production through the downregulation of COX-2 and EGFR in lung cancer cells. (A) PGE ${ }_{2}$ in culture supernatants from the Mel $(10$ and $20 \mu \mathrm{M})$ or vehicle-treated Lewis lung carcinoma and A549 cells were determined by ELISA. (B) p-EGFR and EGFR in the LLC and A549 cells treated with Mel (10 and $20 \mu \mathrm{M})$ or vehicle for 24 hours were determined by Western blot. (C and D) VEGF and TGF- $\beta$ in culture supernatants was determined by ELISA. (E) PD-L1 in the LLC and A549 cells treated as described in Fig. 5B was measured by quantitative PCR. (F) The effects of COX-2 overexpression on COX-2 protein levels in LLC and A549 cells were measured by Western blot. Each value represents the mean \pm S.E.M. of five independent triplicate experiments. ${ }^{*} P<0.05 ; * * P<0.01$ vs. negative control lentivirus (LV-NC). (G) Parental and COX-2 ${ }^{\text {high }}$ LLC and A549 cells were treated with $\mathrm{Mel}(20 \mu \mathrm{M})$ or vehicle for 24 hours, followed by treatment with or without PGE $2(1 \mu \mathrm{M})$ or EGF $(20 \mathrm{ng} / \mathrm{ml})$ for another 24 hours. VEGF and TGF- $\beta$ in culture supernatants were determined by ELISA. (H) PD-L1 in the LLC and A549 cells treated as described in Fig. 5G was measured by Western blot. Each value represents the mean \pm S.E.M. of five independent triplicate experiments. $* P<0.05 ; * * P<0.01$ vs. control, ${ }^{\#} P<0.05 ;{ }^{\# \#} P<$ vs. Mel $(20 \mu \mathrm{M})$-treated group.

analysis to measure the tumor perfusion. As shown in Fig. 3A, Mel (20 and $40 \mathrm{mg} / \mathrm{kg}$ ) notably enhanced LLC tumor perfusion compared with the control. Tumor perfusion in the control mice rose by $4.5 \%$ at day 2 , and rose higher, by $9.7 \%$, at day 4 , and increased slighter by $5.0 \%$ at day 8 compared with tumor perfusion measured at day 0 . Mel (20 and $40 \mathrm{mg} / \mathrm{kg}$ ) steadily increased tumor perfusion until day 4 (25.6\% and $34.0 \%$, respectively), and increased tumor perfusion slightly at day 8 ( $15.7 \%$ and $19.4 \%$, respectively) compared with tumor perfusion measured at day 0 . However, tumor perfusion measured at day 8 showed a rapid decline when compared with that measured at day 4 . These data indicate that Mel could create a short-lived time window of about 5 days when tumor vessels could normalize transiently. We then double-stained the pericyte marker $\alpha$-smooth muscle actin ( $\alpha$-SMA) and the endothelial cell marker CD31 and found that Mel (20 and $40 \mathrm{mg} / \mathrm{kg}$ ) reduced microvessel density but enhanced vessel pericyte coverage in LLC and CMT167 tumors (Fig. 3, B-G). Furthermore, the expression of $\mathrm{HIF}-1 \alpha$ was significantly decreased in response to $\mathrm{Mel}$ (Fig. $3 \mathrm{H}$ ). We also observed the downregulated TGF- $\beta$ and VEGF in the tumor cells from LLC and CMT167 tumors by Mel treatment (Fig. 3I).These data suggest that Mel promotes vascular normalization in the LLC and CMT167 tumors.
Next, we measured the effects of $\mathrm{Mel}$ on $\mathrm{CD}^{+} \mathrm{T}$-cell suppression in LLC and CMT167 tumors. As shown in Fig. 4, $\mathrm{A}$ and $\mathrm{B}, \mathrm{Mel}$ (20 and $40 \mathrm{mg}$ ) significantly reduced the expression of PD-L1 in the tumor cells and enhanced the number of CD8 ${ }^{+}$ $\mathrm{T}$ cells in LLC and CMT167 tumors. We then examined the effector function of $\mathrm{CD}^{+} \mathrm{T}$ cells upon Mel treatment and found that Mel increased the expression of GzmB, IL-2, and IFN- $\gamma$ (Fig. 4, C-F). These results indicate that Mel downregulates PD-L1 in tumor cells and enhances the infiltration and effector function of $\mathrm{CD}^{+}{ }^{+} \mathrm{T}$ cells in LLC and CMT167 tumors.

Mel Downregulates VEGF, TGF- $\beta$, and PD-L1 in Lung Cancer Cells through COX-2 and EGFR Inhibition. We investigated next whether Mel downregulated VEGF, TGF- $\beta$, and PD-L1 in lung cancer cells through both COX-2 and EGFR inhibition. We found that Mel (10 and $20 \mu \mathrm{M})$ did not affect the proliferation of mouse LLC and human A549 lung cancer cells (Supplementary Fig. 3) but decreased the level of $\mathrm{PGE}_{2}$ and p-EGFR with the downregulated VEGF, TGF- $\beta$, and PD-L1 in the LLC and A549 cells (Fig. 5, A-E). By contrast, overexpression of COX-2 or exogenous addition of $\mathrm{PGE}_{2}$ or EGF attenuated these effects (Fig. 5, F-H). These data suggest that Mel downregulated tumor cell-derived VEGF, TGF- $\beta$, and PD-L1 through COX-2 and EGFR inhibition. 


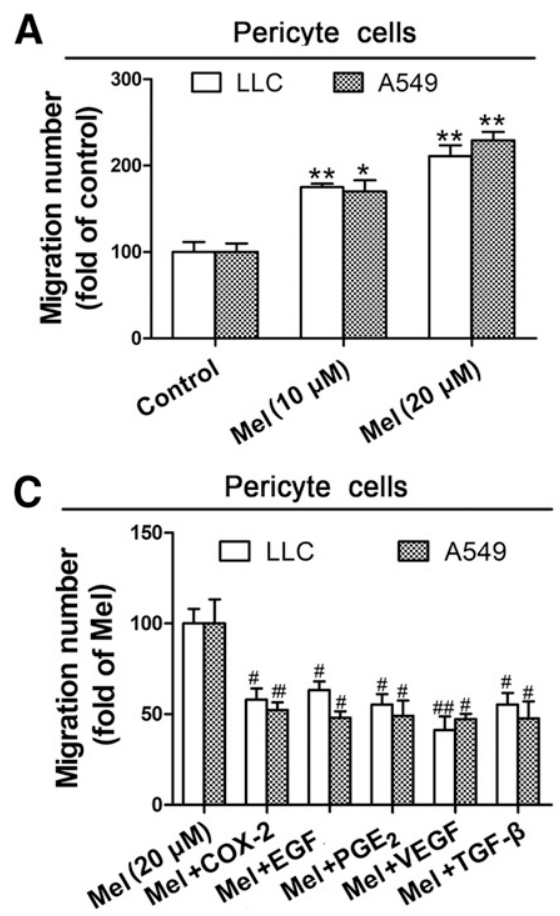

B

Endothelial cells
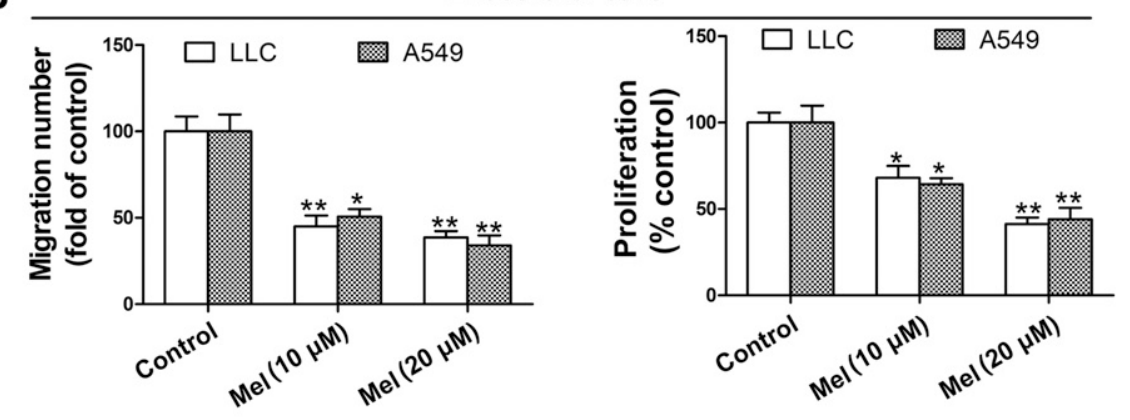

D
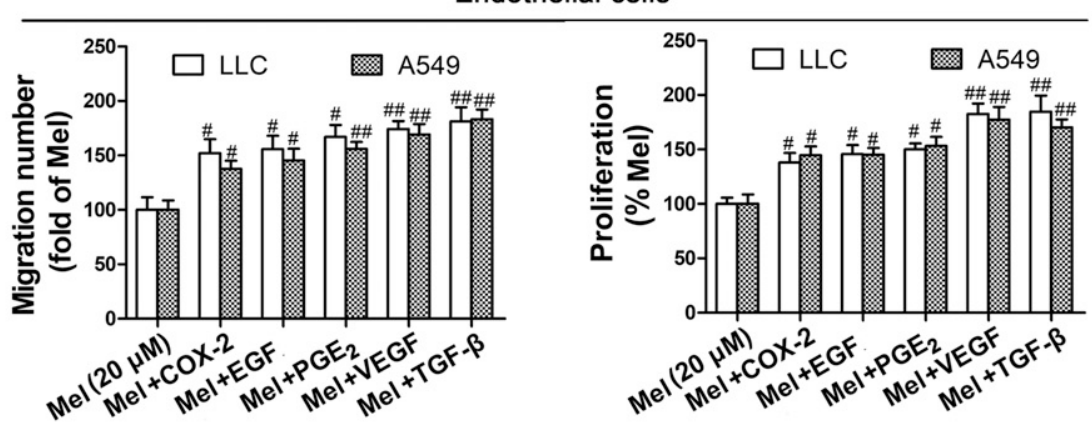

Fig. 6. COX-2 and EGFR inhibition by melafolone increases the migration of pericyte cells and decreases the proliferation and migration of endothelial cells through downregulation of VEGF and TGF- $\beta$. (A and B) Lewis lung carcinoma and A549 cells were treated with Mel (10 and $20 \mu \mathrm{M})$ or vehicle for 24 hours. The condition medium from each group was added to the lower chamber. Pericyte cells (mouse pericyte-like cells, 10T1/2, and human brain vascular pericytes, HBVP) (A) or endothelial cells (mouse endothelial cells, MS1, and human umbilical vein endothelial cells, HUVEC) (B) were added to the upper chamber and then incubated overnight. The cells that migrated to the lower chamber were counted. MS1 or HUVEC was plated at $1 \times 10^{4}$ per well in 96-well culture plates and then treated with the CM. Cell proliferation was measured using MTS assays (B). (C and D) Parental and COX-2 ${ }^{\text {high }}$ LLC and A549 cells were treated with Mel $(20 \mu \mathrm{M})$ or vehicle for 24 hours, followed by treatment with or without PGE 2 (1 $\mu$ M), EGF $(20 \mathrm{ng} / \mathrm{ml})$, VEGF $(20 \mathrm{ng} / \mathrm{ml})$, or TGF- $\beta(10 \mathrm{ng} / \mathrm{ml})$ for another 24 hours. The CM from each group was added to the lower chamber. Pericyte cells (10T1/2 and HBVP) (C) or endothelial cells (MS1 and HUVEC) (D) were added to the upper chamber and then incubated overnight. The cells that migrated to the lower chamber were counted. MS1 or HUVEC were plated at $1 \times 10^{4}$ per well in 96-well culture plates and then treated with the CM. Cell proliferation was measured using MTS assays (D). Each value represents the mean \pm S.E.M. of five independent triplicate experiments. ${ }^{*} P<0.05 ; * * P<0.01$ vs. control, ${ }^{\#} P<0.05 ;{ }^{\# \#} P<0.01$ vs. Mel $(20 \mu \mathrm{M})$-treated group.

COX-2 and EGFR Inhibition by Mel Enhances the Migration of Pericyte Cells and Reduces the Proliferation and Migration of Endothelial Cells through VEGF and TGF- $\beta$ Downregulation. Inhibition of TGF- $\beta$ and VEGF derived from tumor cells contributes to tumor vessel normalization (Joseph et al., 2013; Wouters et al., 2013).We demonstrated that the CM from Mel (10 and $20 \mu \mathrm{M}$ )-treated lung cancer cells increased pericyte cell migration and reduced endothelial cell proliferation and migration (Fig. 6, A and B). However, overexpression of COX-2 and exogenous addition of $\mathrm{PGE}_{2}, \mathrm{EGF}$, TGF- $\beta$, or VEGF attenuated these effects (Fig. 6, C and D). These data indicate that COX-2 and EGFR inhibition by Mel in lung cancer cells enhanced the migration of pericyte cells and reduced the proliferation and migration of endothelial cells through the downregulation of VEGF and TGF- $\beta$.

COX-2 and EGFR Inhibition by Mel Increases the Proliferation and Effector Function of $\mathrm{CDB}^{+} \mathrm{T}$ Cells through PD-L1 Downregulation. Because PD-L1 in tumor cells induces $\mathrm{CD}^{+} \mathrm{T}$-cell anergy and exhaustion (Ramjiawan et al., 2017), we sought to determine whether Mel ameliorates CD8 ${ }^{+}$T-cell suppression via PD-L1 regulation. We observed enhanced proliferation of $\mathrm{CD} 8^{+} \mathrm{T}$ cells and expression of its effector cytokine GzmB, IFN- $\gamma$, and IL-2 when Mel-treated LLC and A549 cells were cocultured with CD8 ${ }^{+}$T cells (Fig. 7,
A and B). By contrast, overexpression of COX-2 or PD-L1 and exogenous addition of EGF or $\mathrm{PGE}_{2}$ partially reversed these effects (Fig. 7, C and D). These results indicate that COX2 and EGFR inhibition by Mel increases the proliferation and effector function of $\mathrm{CD} 8^{+} \mathrm{T}$ cells through PD-L1 downregulation.

PI3K/Akt Signal Contributes to Mel-Mediated VEGF, TGF- $\boldsymbol{\beta}$, and PD-L1 Downregulation. We found that Mel $(10$ and $20 \mu \mathrm{M})$ reduced EP4 expression and Akt phosphorylation in the A549 cells (Fig. 8A). Conversely, overexpression of COX-2 or exogenous addition of $\mathrm{PGE}_{2}$ or EGF attenuated the effect of Mel on Akt phosphorylation (Fig. 8B). To study whether Mel downregulates VEGF, TGF- $\beta$, and PD-L1 via PI3K/Akt, we overexpressed Akt in the A549 cells (Fig. 8C). As shown in Fig. 8, D and E, Akt overexpression reversed Mel $(20 \mu \mathrm{M})$-induced upregulation of TGF- $\beta$,VEGF, and PD-L1 in A549 cells. The CM from the Mel $(20 \mu \mathrm{M})$-treated A549 cells enhanced pericyte cell migration and reduced endothelial cell proliferation and migration, which was reversed by Akt overexpression (Fig. 8, F-H). Of note, Akt overexpression partially reversed $\mathrm{Mel}(20 \mu \mathrm{M})$-induced increase in $\mathrm{CD} 8^{+} \mathrm{T}$-cell number and production of GzmB, IL-2, and IFN- $\gamma$ (Fig. 8, I and J). These data suggest that Mel downregulates VEGF, TGF- $\beta$, and PD-L1 in lung cancer cells mainly via PI3K/Akt signal.

COX-2 and EGFR Inhibition by Mel Improves AntiPD-1 Immunotherapy. We next studied whether dual COX-2 


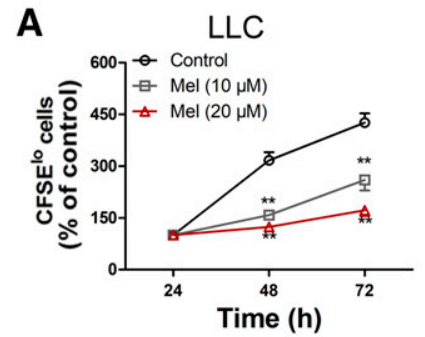

C

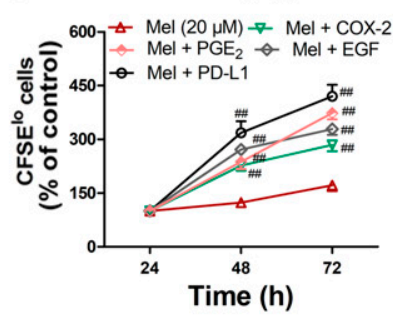

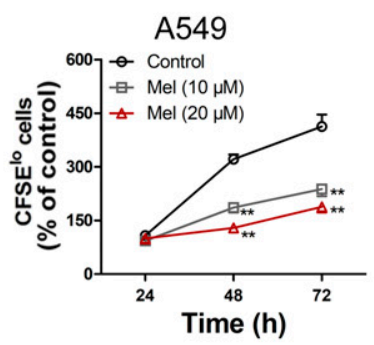

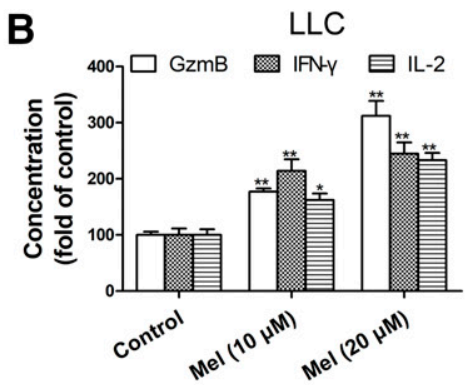

D

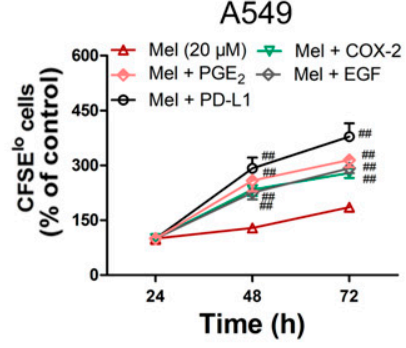

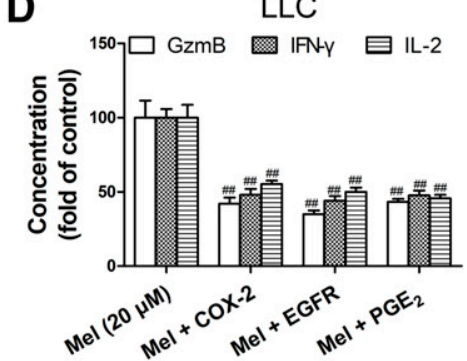

A549

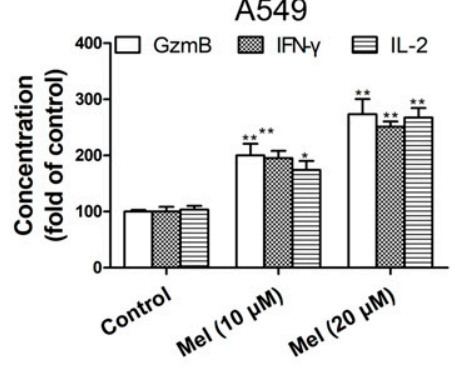

A549

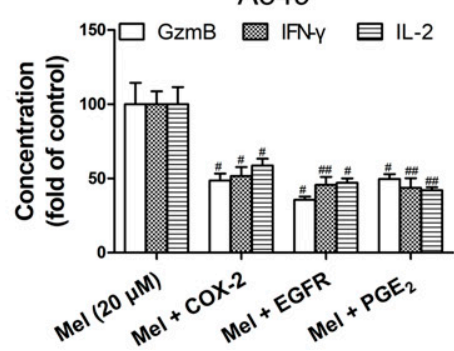

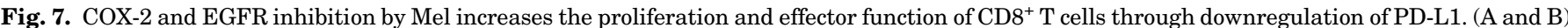

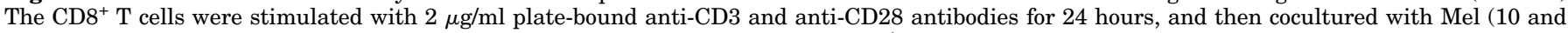

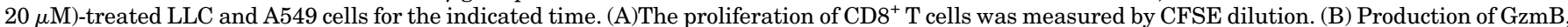

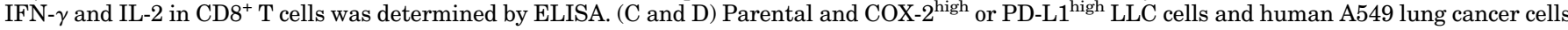

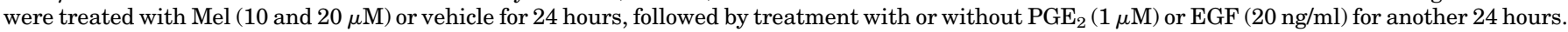

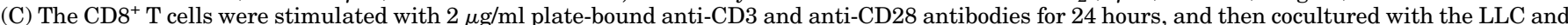

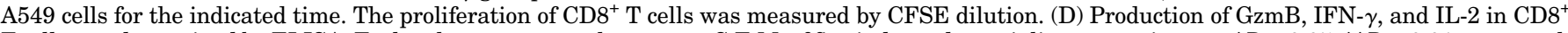

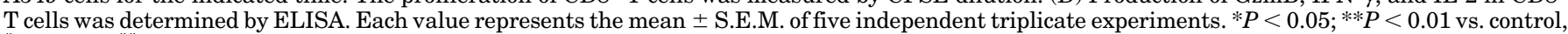
${ }^{\#} P<0.05 ;{ }^{\#} P<$ vs. Mel $(20 \mu \mathrm{M})$-treated group.

and EGFR inhibition by Mel improves PD-1 blockade immunotherapy in LLC and CMT167 tumors. As with previous reports (Lin et al., 2018; Tan et al., 2018), LLC tumors were resistant to anti-PD-1 immunotherapy (Fig. 9, $\mathrm{A}$ and $\mathrm{B})$. Combined Mel with anti-PD-1 treatment greatly reduced tumor weight and prolonged survival compared with the anti-PD-1 therapy (Fig. 9, A and B). In the CMT167 model, tumors were notably restrained, and survival of mice was extended by anti-PD-1 therapy (Fig. 9, C and D). Mel synergized with PD-1 antibody in restraining tumor growth (Fig. 9C) and prolonging survival (Fig. 9D). Compared with the anti-PD-1 monotherapy, the combination of Mel treatment and PD-1 blockade decreased the production of $\mathrm{PGE}_{2}$ and phosphorylation of EGFR and AKT with the downregulated VEGF, TGF- $\beta$, and PD-L1 in the tumor cells from the A549 and LLC tumors (Fig. 9, E-I). The combination arms also reduced microvessel density, enhanced vessel pericyte coverage, and increased the number and effector function of $\mathrm{CD}^{+} \mathrm{T}$ cells in the LLC and CMT167 tumors (Fig. 9, J-M). No significant loss of body weight, impairment of cardiac function, liver function, renal function, and hematopoiesis were observed in the mice bearing-CMT167 tumors treated with Mel for 2 weeks. Anti-PD-1 monotherapy tended to cause impairments of cardiac functions, as characterized by the increases in plasma aspartate aminotransferase and creatine kinase-MB levels, though the difference was not significant. The combination of Mel with anti-PD-1 treatment did not result in any extra toxicity compared with the anti-PD-1 monotherapy (Table 1). These results indicate that dual COX-2 and EGFR inhibition by Mel improves anti-PD-1 immunotherapy for the LLC and CMT167 tumors with few side effects.

\section{Discussion}

Two novel observations have been made in the present study. First, we presented direct evidence that dual COX-2 and EGFR inhibition by a novel flavonoid Mel overcomes resistance to anti-PD-1 immunotherapy in LLC tumors, and improves efficacy of anti-PD-1 immunotherapy in CMT167 tumors. As far as we know, ours was the first investigation that directly illustrates the antitumor immunity effect of Mel. Second, we demonstrated that Mel normalizes tumor vasculature and ameliorates PD-L1-mediated immunosuppression that occurs via COX-2 and EGFR-PI3K/Akt signaling. These findings suggest the vital roles of dual inhibition of COX-2 and EGFR in host antitumor immunity, which could develop into a novel multitarget agency to improve checkpoint blockade therapy for human lung cancer.

Flavonoids are polyphenolic compounds that exert potent antitumor activities with low toxicity (Yang et al., 2015). A previous study in our group showed that flavonoid $\mathrm{CH} 625$ increased survival and decreased tumor burden with enhanced antitumor immunity in C6 and GL261gliomas (Wang et al., 2018). In addition, a recent study from another group has shown that flavone apigenin inhibits PD-L1 expression and enhances T-cell proliferation in breast cancer (Coombs et al., 2016). Here we demonstrated that flavonoid Mel improves anti-PD-1 therapy in the LLC and CMT167 models with few side effects. There are reports of clinically significant side effects in patients receiving nivolumab or pembrolizumab (anti-PD-1 antibody) treatment, including cases of hepatomegaly, interstitial nephritis, as well as pericarditis (Naidoo et al., 2015; Asnani, 2018). Previous studies showed that flavonoids extenuate radiotherapy and chemotherapy-induced toxicities in lung cancer 

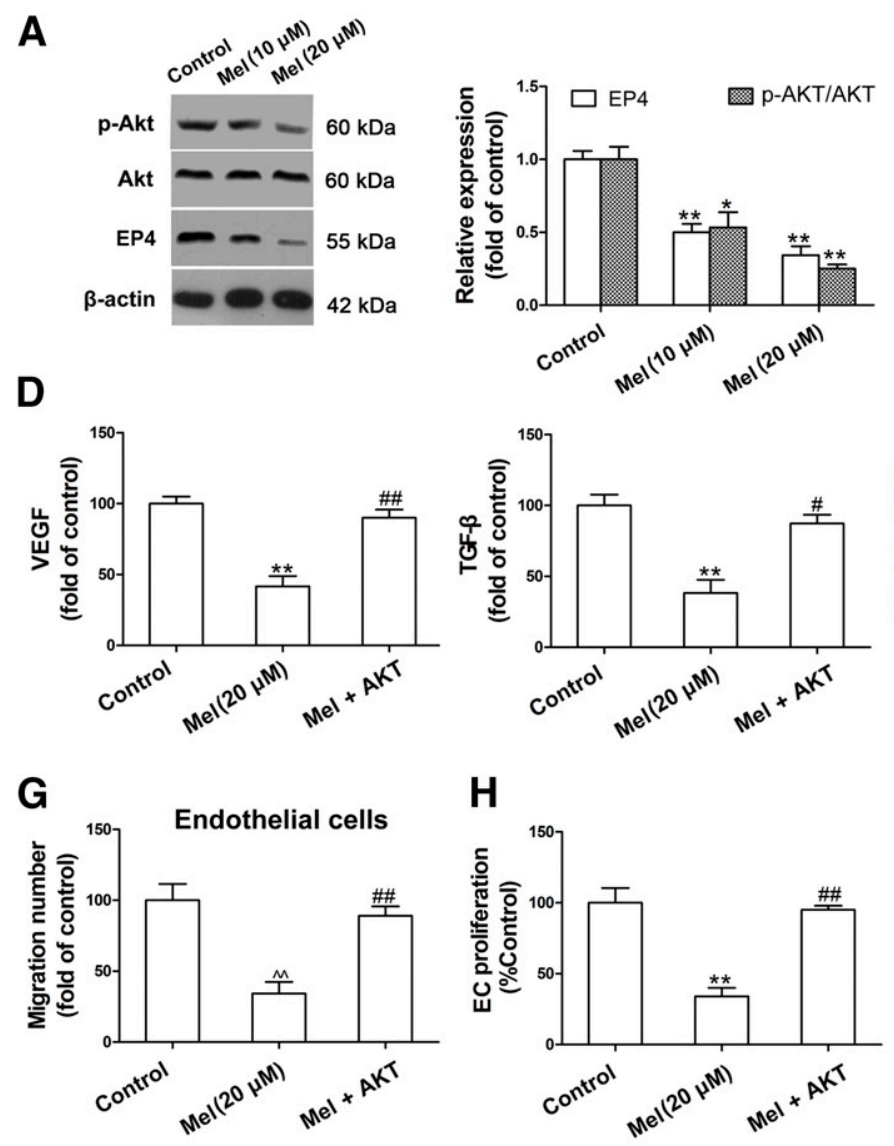
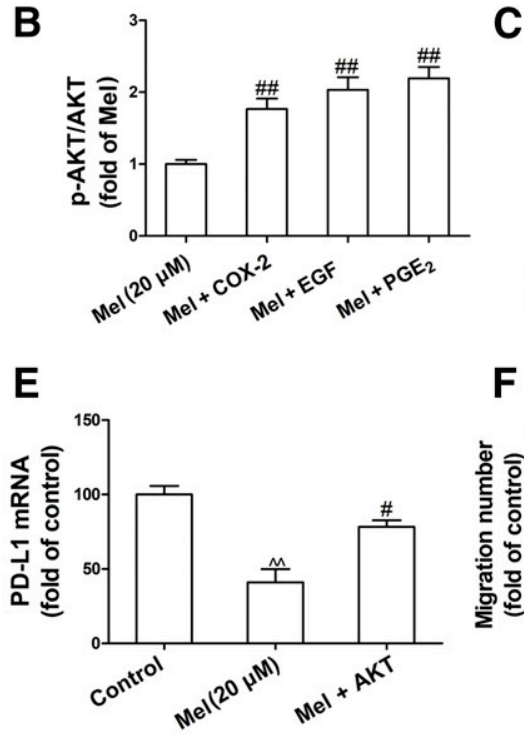

I

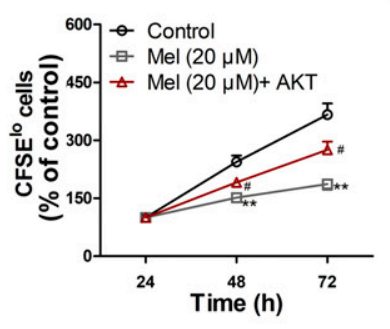



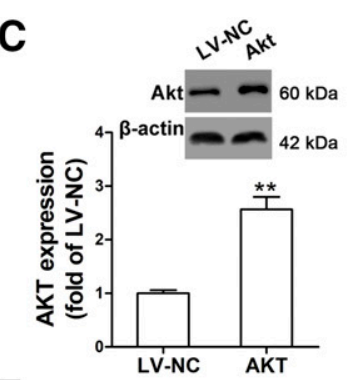

$\mathbf{J}$

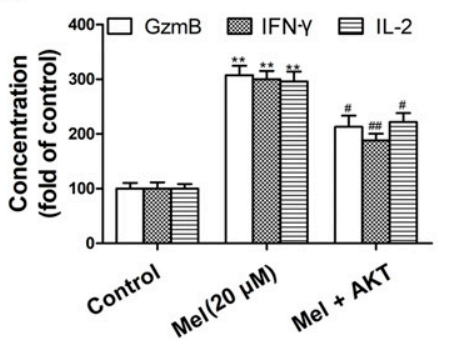

Fig. 8. PI3K/Akt signal contributes to melafolone-mediated downregulation of VEGF, TGF- $\beta$, and PD-L1. (A) A549 cells were treated with Mel (10 and $20 \mu \mathrm{M}$ ) or vehicle for 24 hours. EP4, p-AKT, and AKT were determined by Western blot. (B) Parental and COX-2 ${ }^{\text {high }}$ A549 cells were treated with Mel $(10$ and $20 \mu \mathrm{M})$ or vehicle for 24 hours, followed by treatment with or without $\mathrm{PGE}_{2}(1 \mu \mathrm{M})$ or EGF $(20 \mathrm{ng} / \mathrm{ml})$ for another 24 hours. p-AKT and AKT were determined by Western blot. (C) The effects of Akt overexpression on Akt protein levels in A549 cells were measured by Western blot. (D) Parental and $\mathrm{Akt}^{\text {high }}$ A549 cells treated with Mel $(20 \mu \mathrm{M})$ or vehicle for 24 hours. VEGF and TGF- $\beta$ in the supernatants were determined by ELISA. (E) PD-L1 in the A549 cells treated as described in Fig. 8D was measured by quantitative PCR. (F and G) The condition medium from the A549 cells treated as described in Fig. 8D was added to the lower chamber. Pericyte cells (human brain vascular pericytes, HBVP) or endothelial cells (human umbilical vein endothelial cells, HUVEC) were added to the upper chamber and then incubated overnight. The cells that migrated to the lower chamber were counted. (H) HUVEC were plated at $1 \times 10^{4}$ per well in 96-well culture plates, and then treated with CM described in Fig. 8F. Cell proliferation was measured using MTS assays. (I) The CD8 ${ }^{+} \mathrm{T}$ cells were stimulated with $2 \mu \mathrm{g} / \mathrm{ml}$ plate-bound anti-CD3 and anti-CD28 antibodies for 24 hours, and then cocultured with the A549 cells treated as described in Fig. 8D for the indicated time. The proliferation of CD8 ${ }^{+} \mathrm{T}$ cells was measured by carboxyfluorescein succinimidyl ester dilution. (J) Production of GzmB, IFN- $\gamma$, and IL-2 in CD8 ${ }^{+}$T cells was determined by ELISA. Each value represents the mean \pm S.E.M. of five independent triplicate experiments. ${ }^{*} P<0.05 ;{ }^{* *} P<0.01$ vs. control, ${ }^{\#} P<0.05$; ${ }^{\# \#} P<0.01$ vs. Mel $(20 \mu \mathrm{M})$-treated group.

(Yin et al., 2012; Hillman et al., 2013). Therefore, further studies are being carried out to test whether flavonoid Mel could ameliorate the anti-PD-1-induced toxicities in lung cancer.

COX-2 expression positively correlates with PD-L1 expression in human lung adenocarcinoma (Shimizu et al., 2017). However, COX-2 inhibitor celecoxib did not decrease PD-L1 expression in NSCLC cells (Shimizu et al., 2018), suggesting another pathway that compensates for the effects of COX-2 inhibition. Here we demonstrated that dual COX-2 and EGFR inhibition by Mel downregulated PD-L1 in lung cancer cells in vivo and in vitro. Conversely, these effects were attenuated by exogenous addition of EGF. Previous studies have shown that EGFR is overexpressed in NSCLC and upregulates PD-L1 expression (Gately et al., 2014; Miura and Sunaga, 2018). Increasing evidence indicates a tight connection between the COX-2 and EGFR pathways in lung cancer (Shi et al., 2017). These results suggest that a highly activated EGFR pathway might compensate for the effects of COX-2 blockade on PD-L1. PD-L1-mediated suppression of activated $\mathrm{CD}^{+} \mathrm{T}$ cells is crucial for tumor escape from immune attack on cancer progression (Wang et al., 2016). Here we demonstrated that dual COX-2 and EGFR inhibition by Mel increases the proliferation and effector function of $\mathrm{CD} 8^{+}$ T cells through PD-L1 downregulation. These results suggest that the dual COX-2 and EGFR inhibition by Mel ameliorates PD-L1-mediated immunosuppression and could be a novel strategy for cancer immunotherapy.

"Vascular normalization" reconditions the tumor immune microenvironment and enhances immunotherapy including antitumor vaccination or adoptive T-cell therapy (Shrimali et al., 2010; Johansson et al., 2012). Here we demonstrated that dual COX-2 and EGFR inhibition by Mel in lung cancer cells normalized tumor vasculature and was accompanied by an increased number of tumor-infiltrated $\mathrm{CD}^{+} \mathrm{T}$ cells, thereby facilitating anti-PD-1 treatment in mice bearing LLC or CMT167 tumors. Moreover, dual COX-2 and EGFR inhibition by Mel promoted vascular normalization through 
LLC

A

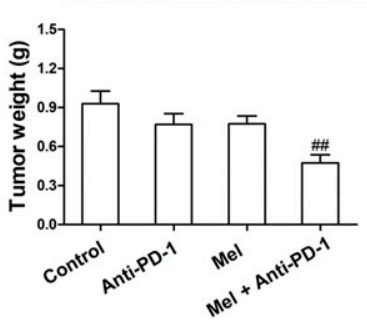

B $\quad 125 \div$ Control $\rightarrow$ Anti-PD-1

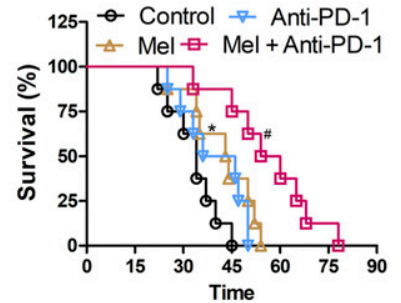

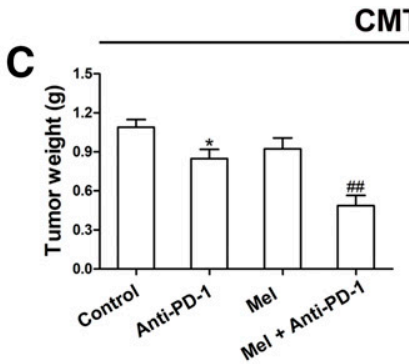

CMT167
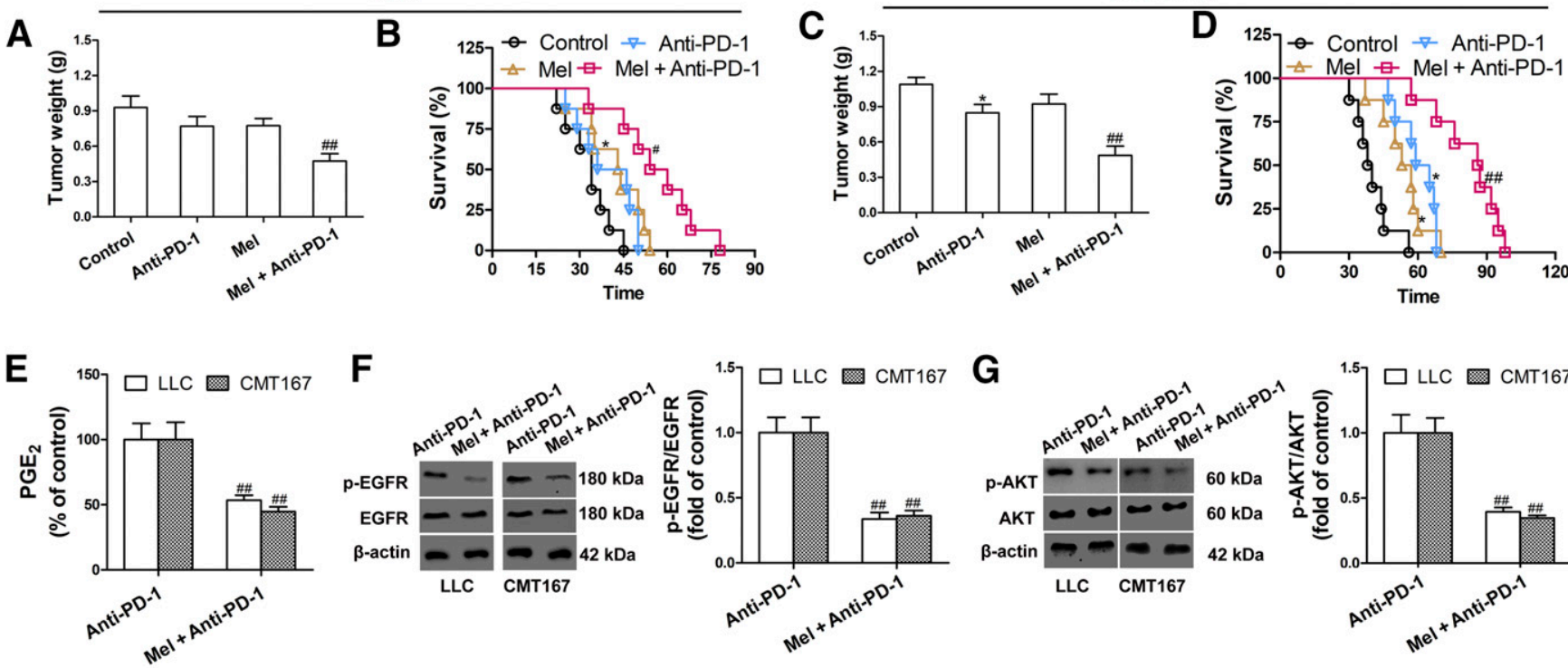

$\mathbf{F}$
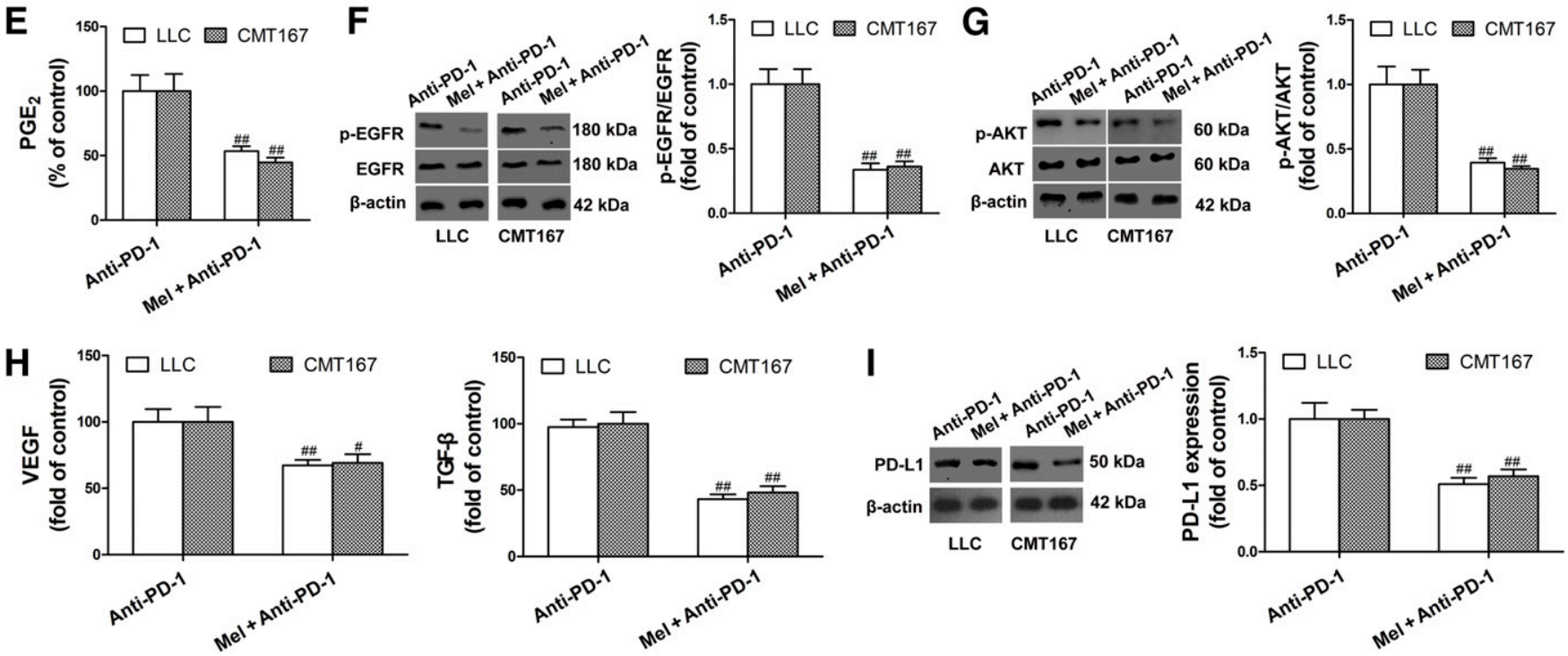

$\mathbf{J}$
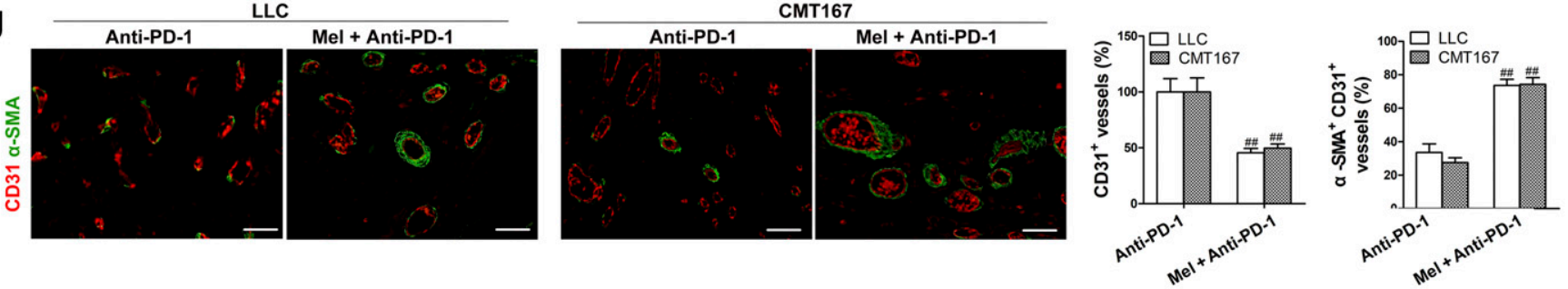

LLC
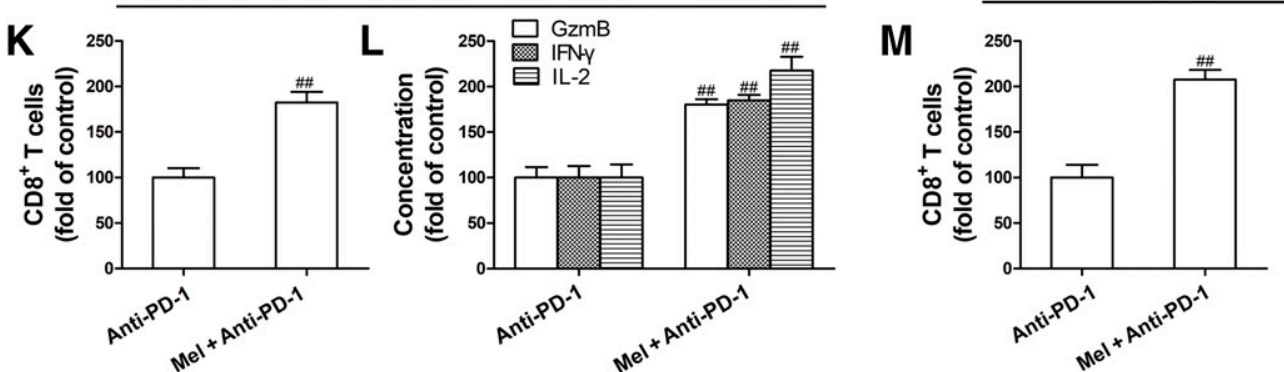

CMT167

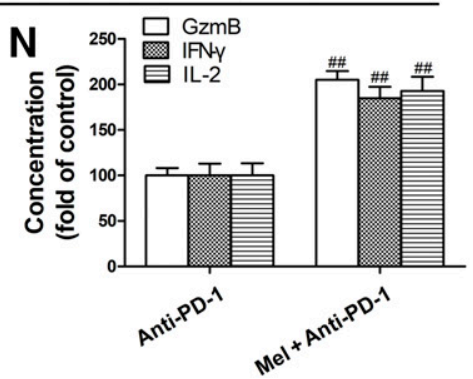

Fig. 9. COX-2 and EGFR inhibition by melafolone improves anti-PD-1 therapy in the Lewis lung carcinoma and CMT167 models. (A) LLC $\left(2 \times 10^{5}\right)$ were injected subcutaneously into the right flank of C57BL/6 mice. When tumors had reached a size of about $100 \mathrm{~mm}^{3}$, the mice were treated with anti-PD-1 antibody (200 $\mu \mathrm{g} /$ mouse every 3 days, i.p.), Mel (20 mg/kg daily, i.p.), anti-PD-1 antibody plus Mel, or vehicle for 7 days. The tumor weight of mice was measured. (B) The survival time of mice was measured. (C) CMT167 $\left(2 \times 10^{5}\right)$ were injected subcutaneously into the right flank of C57BL/6 mice. When tumors had reached a size of about $100 \mathrm{~mm}^{3}$, the mice were treated with anti-PD-1 antibody (200 $\mu \mathrm{g} / \mathrm{mouse}$ every $3 \mathrm{days}$, i.p.), Mel (20 mg/kg daily, i.p.), anti-PD-1 antibody plus melafolone, or vehicle for 14 days. The tumor weight of mice was measured. (D) The survival time of mice was measured. (E) $\mathrm{PGE}_{2}$ in the tumor cells from the LLC and CMT167 tumors was determined by ELISA. (F) p-EGFR and EGFR in the tumor cells from the LLC and CMT167 tumors by Western blot. (G) p-AKT and AKT in the tumor cells from the LLC and CMT167 tumors by Western blot. (H) VEGF and TGF- $\beta$ in the tumor cells from LLC and CMT167 tumors were measured by ELISA. (I) PD-L1 in the tumor cells from LLC and CMT167 tumors was measured by Western blot. (J) Double staining for CD31 (red) and $\alpha$-smooth muscle actin (green) in the LLC and CMT167 tumor tissues was shown. Scale bar, $50 \mu \mathrm{m}$. Quantitative analysis of CD31 ${ }^{+}$vessels and CD $31^{+} \alpha-\mathrm{SMA}^{+}$vessels in the LLC and CMT167 tumor tissues. (K) The number of CD8 ${ }^{+}$T cells in the LLC tumors was determined by flow cytometry. (L) GzmB, IFN- $\gamma$, and IL-2 in the CD8 ${ }^{+} \mathrm{T}$ cells from the LLC tumors were determined by ELISA. (M) The number of $\mathrm{CD}^{+} \mathrm{T}$ cells in the CMT167 tumors was determined by flow cytometry. (N) GzmB, IFN- $\gamma$, and IL-2 in the CD8 ${ }^{+} \mathrm{T}$ cells from the CMT167 tumors were determined by ELISA. The values are presented as the mean \pm S.E.M., $n=8,{ }^{*} P<0.05 ;{ }^{* *} P<0.01$ vs. control. ${ }^{\#} P<0.05 ;{ }^{\# \#} P<0.01$ vs. anti-PD-1-treated group. 
TABLE 1

Effect of melafolone and anti-PD-1 therapy on body weight profile, biochemical profile and complete blood counts in the CMT167 tumor model The CMT167 cells $\left(2 \times 10^{5}\right)$ were injected subcutaneously into the right flank of C57BL/6 mice. Seven days later when tumors had reached a size of about $100 \mathrm{~mm}^{3}$, the mice were treated with anti-PD-1 (200 $\mu \mathrm{g} /$ mouse every 3 days, i.p.), $\mathrm{Mel}(20 \mathrm{mg} / \mathrm{kg}$ daily, i.p.), anti-PD-1 antibody ( $200 \mu \mathrm{g} / \mathrm{mouse}$ every 3 days, i.p.) plus Mel ( $20 \mathrm{mg} / \mathrm{kg}$ daily, i.p.), or vehicle for 14 days. The plasma aspartate aminotransferase (AST), alanine aminotransferase (ALT), blood urea nitrogen (BUN), creatine levels, creatine kinase-MB (CK-MB), and complete blood counts, including white blood corpuscles (WBC), red blood corpuscles (RBC), hematocrit (HCT), mean cell volume (MCV), and platelet (PLT) levels, were determined. Data are presented as mean \pm S.E.M., $n=8$.

\begin{tabular}{|c|c|c|c|c|}
\hline Groups & Control & Anti-PD-1 & Mel & Mel+ Anti-PD-1 \\
\hline Body weight (g) & $26.3 \pm 0.6$ & $26.6 \pm 0.6$ & $26.6 \pm 0.5$ & $27.1 \pm 0.7$ \\
\hline ALT (IU/1) & $35.6 \pm 1.8$ & $35.9 \pm 2.1$ & $35.1 \pm 1.7$ & $37.9 \pm 1.8$ \\
\hline BUN (mg/dl) & $26.4 \pm 2.7$ & $26.9 \pm 2.1$ & $28.3 \pm 3.2$ & $27.5 \pm 2.1$ \\
\hline CK-MB (IU/l) & $119.1 \pm 11.2$ & $155.9 \pm 12.9$ & $114.6 \pm 9.1$ & $122.2 \pm 10.1$ \\
\hline $\operatorname{RBC}\left(\times 10^{12} / 1\right)$ & $8.3 \pm 0.3$ & $8.2 \pm 0.2$ & $8.1 \pm 0.1$ & $8.1 \pm 0.2$ \\
\hline WBC $\left(\times 10^{9} /\right)$ & $3.8 \pm 0.2$ & $3.6 \pm 0.3$ & $3.8 \pm 0.2$ & $3.6 \pm 0.2$ \\
\hline
\end{tabular}

VEGF or TGF- $\beta$ downregulation in lung cancer cells. We previously reported that the downregulated TGF- $\beta$ and VEGF in endothelial progenitor cells (EPCs) and TAMs contributes to gliomal vascular normalization (Wang et al., 2017a). Therefore, we conclude that COX-2 and EGFR inhibition by Mel normalizes tumor vasculature through VEGF or TGF- $\beta$ downregulation in cells other than tumor cells in a tumor microenvironment. Further research is being conducted to explore the possibilities.

PI3K/Akt is a crucial signal in tumor angiogenesis (Chen et al., 2017b). We previously reported that the downregulation of PI3K/Akt in TAMs and EPCs promotes gliomal vascular normalization (Wang et al., 2017a). Here we found that dual COX-2 and EGFR inhibition by Mel reduced proliferation and migration of endothelial cells and enhanced migration of pericyte cells through PI3K/Akt downregulation. PI3K/Akt activation upregulates PD-L1 expression in human lung cancer cells (Zhang et al., 2017), and inhibition of PI3K/Akt signaling exerts antitumor immunity (O'Donnell et al., 2018). In this study, we demonstrated that dual COX-2 and EGFR inhibition by Mel decreased PD-L1 expression in lung cancer cells and increased effector function of $\mathrm{CD} 8^{+}$ $\mathrm{T}$ cells, whereas Akt overexpression attenuated these effects. These data indicate that dual COX-2 and EGFR blockade by $\mathrm{Mel}$ induces vascular normalization and ameliorates PD-L1-mediated immunosuppression via PI3K/Akt pathway.

In summary, dual inhibition of COX-2 and EGFR by flavonoid Mel improves anti-PD-1 therapy through vascular normalization and PD-L1 downregulation via the PI3K/Akt pathway. We identify flavonoid Mel as the dual inhibitor of COX-2 and EGFR, by which Mel improves anti-PD-1 therapy with few side effects. Our results may lay a solid foundation for the development of $\mathrm{Mel}$ as a novel candidate agent against resistance to checkpoint blockade therapy for human lung cancer.

\section{Authorship Contributions}

Participated in research design: Tang, Zheng, J. Yang.

Conducted experiments: Tang, Y. Liu, Wang, Zheng, Y. Chen, W. Liu, X. Chen.

Performed data analysis: Tang, H. Chen, Zhang.

Wrote or contributed to the writing of the manuscript: Tang, J. Yang, Y. Yang, Y. Liu.

\section{References}

Alanazi AM, El-Azab AS, Al-Suwaidan IA, ElTahir KEH, Asiri YA, Abdel-Aziz NI, and Abdel-Aziz AAM (2015) Structure-based design of phthalimide derivatives as potential cyclooxygenase-2 (COX-2) inhibitors: anti-inflammatory and analgesic activities. Eur J Med Chem 92:115-123.

Allen E, Jabouille A, Rivera LB, Lodewijckx I, Missiaen R, Steri V, Feyen K, Tawney J, Hanahan D, Michael IP, et al. (2017) Combined antiangiogenic and anti-PD-L1 therapy stimulates tumor immunity through HEV formation. Sci Transl Med $\mathbf{9}$. Arfaoui A, Kriaa L, Znaidi N, Gritli S, Bouacha H, Zermani R, and Rammeh S (2014) Over-expression of EGFR is closely correlated to poor prognosis in Tunisian patients with non-small cell lung adenocarcinoma. J Immunoassay Immunochem $\mathbf{3 5}$ : $256-268$.

Asnani A (2018) Cardiotoxicity of immunotherapy: incidence, diagnosis, and management. Curr Oncol Rep 20:44.

Blobaum AL and Marnett LJ (2007) Structural and functional basis of cyclooxygenase inhibition. $J$ Med Chem 50:1425-1441.

Chen XW, Yu TJ, Zhang J, Li Y, Chen HL, Yang GF, Yu W, Liu YZ, Liu XX, Duan CF, et al. (2017a) CYP4A in tumor-associated macrophages promotes pre-metastatic niche formation and metastasis. Oncogene 36:5045-5057.

Chen Y, Li C, Xie H, Fan Y, Yang Z, Ma J, He D, and Li L (2017b) Infiltrating mast cells promote renal cell carcinoma angiogenesis by modulating $\mathrm{PI} 3 \mathrm{~K} \rightarrow \mathrm{AKT} \rightarrow \mathrm{GSK} 3 \beta \rightarrow \mathrm{AM}$ signaling. Oncogene 36:2879-2888,

Chen Y, Ramjiawan RR, Reiberger T, Ng MR, Hato T, Huang Y, Ochiai H, Kitahara S, Unan EC, Reddy TP, et al. (2015) CXCR4 inhibition in tumor microenvironment facilitates anti-programmed death receptor-1 immunotherapy in sorafenib-treated hepatocellular carcinoma in mice. Hepatology 61:1591-1602.

Chowdhury PS, Chamoto K, Kumar A, and Honjo T (2018) PPAR-induced fatty acid oxidation in $\mathrm{T}$ cells increases the number of tumor-reactive $\mathrm{CD} 8^{+} \mathrm{T}$ cells and facilitates anti-PD-1 therapy. Cancer Immunol Res 6:1375-1387.

Coombs MRP, Harrison ME, and Hoskin DW (2016) Apigenin inhibits the inducible expression of programmed death ligand 1 by human and mouse mammary carcinoma cells. Cancer Lett 380:424-433.

Dai J, Liang K, Zhao S, Jia W, Liu Y, Wu H, Lv J, Cao C, Chen T, Zhuang S, et al. (2018) Chemoproteomics reveals baicalin activates hepatic CPT1 to ameliorate diet-induced obesity and hepatic steatosis. Proc Natl Acad Sci USA 115: E5896-E5905.

Duan C, Liu Y, Li Y, Chen H, Liu X, Chen X, Yue J, Zhou X, and Yang J (2018) Sulfasalazine alters microglia phenotype by competing endogenous RNA effect of miR-136-5p and long non-coding RNA HOTAIR in cuprizone-induced demyelination. Biochem Pharmacol 155:110-123.

Ebben JD, Lubet RA, Gad E, Disis ML, and You M (2016) Epidermal growth factor receptor derived peptide vaccination to prevent lung adenocarcinoma formation: an in vivo study in a murine model of EGFR mutant lung cancer. Mol Carcinog 55: $1517-1525$

Ezhilan BP and Neelamegam R (2012) GC-MS analysis of phytocomponents in the ethanol extract of Polygonum chinense L. Pharmacognosy Res 4:11-14.

Gately K, Forde L, Cuffe S, Cummins R, Kay EW, Feuerhake F, and O'Byrne KJ (2014) High coexpression of both EGFR and IGF1R correlates with poor patient prognosis in resected non-small-cell lung cancer. Clin Lung Cancer 15: $58-66$.

Hillman GG, Singh-Gupta V, Hoogstra DJ, Abernathy L, Rakowski J, Yunker CK, Rothstein SE, Sarkar FH, Gadgeel S, Konski AA, et al. (2013) Differential effect of soy isoflavones in enhancing high intensity radiotherapy and protecting lung tissue in a pre-clinical model of lung carcinoma. Radiother Oncol 109:117-125.

Johansson A, Hamzah J, Payne CJ, and Ganss R (2012) Tumor-targeted TNF $\alpha$ stabilizes tumor vessels and enhances active immunotherapy. Proc Natl Acad Sci USA 109:7841-7846.

Joseph JV, Balasubramaniyan V, Walenkamp A, and Kruyt FAE (2013) TGF- $\beta$ as a therapeutic target in high grade gliomas - promises and challenges. Biochem Pharmacol 85:478-485.

Kikuchi O, Ohashi S, Horibe T, Kohno M, Nakai Y, Miyamoto S, Chiba T, Muto M, and Kawakami K (2016) Novel EGFR-targeted strategy with hybrid peptide against oesophageal squamous cell carcinoma. Sci Rep 6:22452. 
Lewandowska H, Kalinowska M, Lewandowski W, Stępkowski TM, and Brzóska K (2016) The role of natural polyphenols in cell signaling and cytoprotection against cancer development. J Nutr Biochem 32:1-19.

Li S, Sun X, Zhao H, Tang Y, and Lan M (2012) Discovery of novel EGFR tyrosine kinase inhibitors by structure-based virtual screening. Bioorg Med Chem Lett 22 4004-4009.

Li X, Lian Z, Wang S, Xing L, and Yu J (2018) Interactions between EGFR and PD-1/PD-L1 pathway: implications for treatment of NSCLC. Cancer Lett 418 $1-9$

Li Y, Zhao H, Wang Y, Zheng H, Yu W, Chai H, Zhang J, Falck JR, Guo AM, Yue J, et al. (2013) Isoliquiritigenin induces growth inhibition and apoptosis through downregulating arachidonic acid metabolic network and the deactivation of PI3K Akt in human breast cancer. Toxicol Appl Pharmacol 272:37-48.

Li YX, Wang JL, Gao M, Tang H, Gui R, and Fu YF (2016) Celecoxib-erlotinib combination delays growth and inhibits angiogenesis in EGFR-mutated lung cancer. Am $J$ Cancer Res 6:1494-1510.

Lin H, Wei S, Hurt EM, Green MD, Zhao L, Vatan L, Szeliga W, Herbst R, Harms PW, Fecher LA, et al. (2018) Host expression of PD-L1 determines efficacy of PD-L1 pathway blockade-mediated tumor regression. J Clin Invest 128: 805-815.

Liu Y, Duan C, Chen H, Wang C, Liu X, Qiu M, Tang H, Zhang F, Zhou X, and Yang J (2018) Inhibition of COX-2/mPGES-1 and 5-LOX in macrophages by leonurine ameliorates monosodium urate crystal-induced inflammation. Toxicol Appl Pharmacol 351:1-11.

Meyers DE, Bryan PM, Banerji S, and Morris DG (2018) Targeting the PD-1/PD-L1 axis for the treatment of non-small-cell lung cancer. Curr Oncol 25:e324-e334.

Miura Y and Sunaga N (2018) Role of immunotherapy for oncogene-driven non-small cell lung cancer. Cancers (Basel) 10:e245.

Naidoo J, Page DB, Li BT, Connell LC, Schindler K, Lacouture ME, Postow MA and Wolchok JD (2015) Toxicities of the anti-PD-1 and anti-PD-L1 immune checkpoint antibodies. Ann Oncol 26:2375-2391.

O’Donnell JS, Long GV, Scolyer RA, Teng MWL, and Smyth MJ (2017) Resistance to PD1/PDL1 checkpoint inhibition. Cancer Treat Rev 52:71-81.

O'Donnell JS, Massi D, Teng MWL, and Mandala M (2018) PI3K-AKT-mTOR inhibition in cancer immunotherapy, redux. Semin Cancer Biol 48:91-103.

Prima V, Kaliberova LN, Kaliberov S, Curiel DT, and Kusmartsev S (2017) COX2/ mPGES1/PGE2 pathway regulates PD-L1 expression in tumor-associated macrophages and myeloid-derived suppressor cells. Proc Natl Acad Sci USA 114: 1117-1122.

Qin T, Wang C, Chen X, Duan C, Zhang X, Zhang J, Chai H, Tang T, Chen H, Yue J, et al. (2015) Dopamine induces growth inhibition and vascular normalization through reprogramming M2-polarized macrophages in rat C6 glioma. Toxicol Appl Pharmacol 286:112-123.

Raju S, Joseph R, and Sehgal S (2018) Review of checkpoint immunotherapy for the management of non-small cell lung cancer. ImmunoTargets Ther 7:63-75.

Ramjiawan RR, Griffioen AW, and Duda DG (2017) Anti-angiogenesis for cancer revisited: is there a role for combinations with immunotherapy? Angiogenesis 20: 185-204.

Ruf M, Moch H, and Schraml P (2016) PD-L1 expression is regulated by hypoxia inducible factor in clear cell renal cell carcinoma. Int J Cancer 139:396-403.

Selvaggi G, Novello S, Torri V, Leonardo E, De Giuli P, Borasio P, Mossetti C, Ardissone F, Lausi P, and Scagliotti GV (2004) Epidermal growth factor receptor overexpression correlates with a poor prognosis in completely resected non-smallcell lung cancer. Ann Oncol 15:28-32.

Shi Q, Jiang Z, Yang J, Cheng Y, Pang Y, Zheng N, Chen J, Chen W, and Jia L (2017) A flavonoid glycoside compound from murraya paniculata (L.) interrupts metastatic characteristics of A549 cells by regulating STAT3/NF-кB/COX-2 and EGFR signaling pathways. AAPS J 19:1779-1790.

Shimizu K, Okita R, Saisho S, Maeda A, Nojima Y, and Nakata M (2017) Prognostic value of Cox-2 and PD-L1 expression and its relationship with tumorinfiltrating lymphocytes in resected lung adenocarcinoma. Cancer Manag Res 9: 741-750.
Shimizu K, Okita R, Saisho S, Maeda AI, Nojima Y, and Nakata M (2018) Impact of COX2 inhibitor for regulation of PD-L1 expression in non-small cell lung cancer. Anticancer Res 38:4637-4644.

Shrimali RK, Yu Z, Theoret MR, Chinnasamy D, Restifo NP, and Rosenberg SA (2010) Antiangiogenic agents can increase lymphocyte infiltration into tumor and enhance the effectiveness of adoptive immunotherapy of cancer. Cancer Res 70: 6171-6180.

Siegel RL, Miller KD, and Jemal A (2016) Cancer statistics, 2016. CA Cancer J Clin 66:7-30.

Siemann DW and Horsman MR (2015) Modulation of the tumor vasculature and oxygenation to improve therapy. Pharmacol Ther 153:107-124.

Sogabe S, Kawakita Y, Igaki S, Iwata H, Miki H, Cary DR, Takagi T, Takagi S, Ohta $\mathrm{Y}$, and Ishikawa T (2012) Structure-based approach for the discovery of pyrrolo[3,2d]pyrimidine-based EGFR T790M/L858R mutant Inhibitors. ACS Med Chem Lett 4:201-205

Takac P, Kello M, Pilatova MB, Kudlickova Z, Vilkova M, Slepcikova P, Petik P, and Mojzis $J$ (2018) New chalcone derivative exhibits antiproliferative potential by inducing G2/M cell cycle arrest, mitochondrial-mediated apoptosis and modulation of MAPK signalling pathway. Chem Biol Interact 292:37-49.

Tan B, Shi X, Zhang J, Qin J, Zhang N, Ren H, Qian M, Siwko S, Carmon K, Liu Q, et al. (2018) Inhibition of Rspo-Lgr4 facilitates checkpoint blockade therapy by switching macrophage polarization. Cancer Res 78:4929-4942.

Wallin JJ, Bendell JC, Funke R, Sznol M, Korski K, Jones S, Hernandez G, Mier J, He X, Hodi FS, et al. (2016) Atezolizumab in combination with bevacizumab enhances antigen-specific T-cell migration in metastatic renal cell carcinoma. Nat Commun 7:12624.

Wang C, Li Y, Chen H, Huang K, Liu X, Qiu M, Liu Y, Yang Y, and Yang J (2018) CYP4X1 inhibition by flavonoid CH625 normalizes glioma vasculature through reprogramming TAMs via CB2 and EGFR-STAT3 Axis. J Pharmacol Exp Ther 365:72-83.

Wang C, Li Y, Chen H, Zhang J, Zhang J, Qin T, Duan C, Chen X, Liu Y, Zhou X, et al. (2017a) Inhibition of CYP4A by a novel flavonoid FLA-16 prolongs survival and normalizes tumor vasculature in glioma. Cancer Lett 402:131-141.

Wang J, Jia Y, Zhao S, Zhang X, Wang X, Han X, Wang Y, Ma M, Shi J, and Liu L (2017b) BIN1 reverses PD-L1-mediated immune escape by inactivating the c-MYC and EGFR/MAPK signaling pathways in non-small cell lung cancer. Oncogene 36: $6235-6243$.

Wang S, Campos J, Gallotta M, Gong M, Crain C, Naik E, Coffman RL, and Guiducci $\mathrm{C}$ (2016) Intratumoral injection of a CpG oligonucleotide reverts resistance to PD-1 blockade by expanding multifunctional CD8 + T cells. Proc Natl Acad Sci USA 113: E7240-E7249.

Wouters A, Boeckx C, Vermorken JB, Van den Weyngaert D, Peeters M, and Lardon $\mathrm{F}$ (2013) The intriguing interplay between therapies targeting the epidermal growth factor receptor, the hypoxic microenvironment and hypoxia-inducible factors. Curr Pharm Des 19:907-917.

Yang C, Gundala SR, Mukkavilli R, Vangala S, Reid MD, and Aneja R (2015) Synergistic interactions among flavonoids and acetogenins in Graviola (Annona muricata) leaves confer protection against prostate cancer. Carcinogenesis 36:656-665.

Yin H, Guo R, Xu Y, Zheng Y, Hou Z, Dai X, Zhang Z, Zheng D, and Xu H (2012) Synergistic antitumor efficiency of docetaxel and curcumin against lung cancer. Acta Biochim Biophys Sin (Shanghai) 44:147-153.

Zhang X, Zeng Y, Qu Q, Zhu J, Liu Z, Ning W, Zeng H, Zhang N, Du W, Chen C, et al. (2017) PD-L1 induced by IFN- $\gamma$ from tumor-associated macrophages via the JAK/ STAT3 and PI3K/AKT signaling pathways promoted progression of lung cancer Int J Clin Oncol 22:1026-1033.

Address correspondence to: Dr. Jing Yang, Department of Pharmacology, School of Basic Medical Sciences, Wuhan University, 185 Donghu Road, Wuhan 430071, China. E-mail: jing_yang@whu.edu.cn; yangjingliu2013@ 163.com 